\title{
Processo cuidativo ao paciente cardíaco pós-cirúrgico na Atenção Primária à Saúde: revisão integrativa
}

\author{
Care process to the cardiac patient post-surgery in Primary Health Care: integrative review \\ Proceso de atención al paciente cardíaco posquirúrgico en Atención Primaria de Salud: una \\ revisión integradora
}

Recebido: 01/04/2021 | Revisado: 05/03/2021 | Aceito: 05/04/2021 | Publicado: 09/04/2021

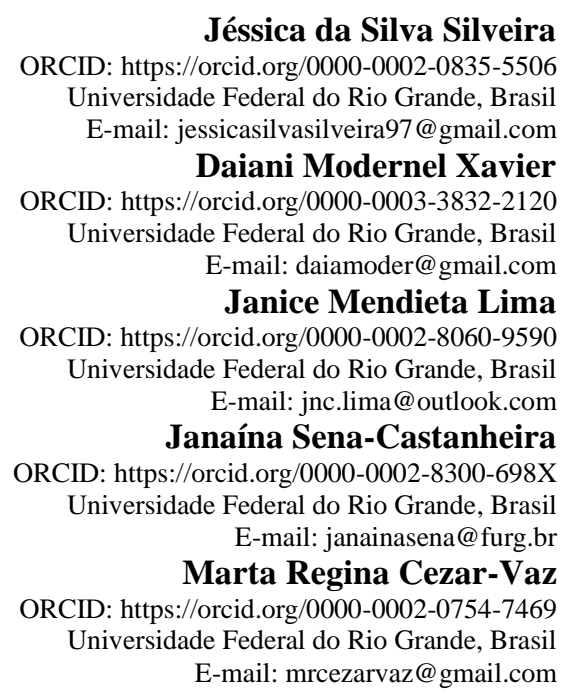

\section{Resumo}

Pacientes crônicos e que foram submetidos a um procedimento cirúrgico encontram-se em um período de fragilidade. Frente a isto, o enfermeiro na Atenção Primária à Saúde possui um papel importante no processo cuidativo, pois necessita dispor de habilidades para fortificar o paciente, ajudando-o a enfrentar dificuldades referentes a sua doença, promovendo sua segurança e autoconfiança. Sendo de particularidade deste profissional, o olhar diferenciado ao paciente, analisando-o como um ser biopsicossocial. A partir dessa realidade, objetiva-se com este estudo, evidenciar a produção científica acerca do processo cuidativo de enfermagem ao paciente cardíaco pós-cirúrgico na Atenção Primária à Saúde. Trata-se de uma Revisão Integrativa de Literatura, que busca o aprofundamento acerca da temática de interesse, por meio de análise e síntese de estudos primários. $\mathrm{O}$ desenvolvimento deste estudo ocorreu em cinco etapas: formulação do problema, pesquisa de literatura, avaliação dos dados, análise dos dados e apresentação. Referente aos resultados, verificou-se que os pacientes acometidos por doenças cardiovasculares e submetidos à cirurgia cardíaca, estão sujeitos a enfrentar diversas alterações em sua vida, envolvendo aspectos físicos, emocionais e psicossociais. Por fim, percebeu-se que por meio de técnicas assistenciais relevantes, como a escuta terapêutica, e pelo olhar diferenciado do enfermeiro, compreendendo o paciente como um ser amplo e complexo, a assistência de enfermagem na Atenção Primária à Saúde apresenta-se de forma diferenciada, resultando em uma aplicação positiva para o processo cuidativo desse grupo de pacientes.

Palavras-chave: Processo de enfermagem; Atenção primária à saúde; Continuidade da assistência ao paciente; Cirurgia torácica.

\begin{abstract}
Chronic patients who have undergone a surgical procedure are in a period of fragility. In view of this, the nurse in Primary Health Care has an important role in the care process, as he needs to have skills to fortify the patient, helping him to face difficulties related to his disease, promoting his security and self-confidence. Being of this professional's particularity, the patient's different look, analyzing him as a biopsychosocial being. Based on this reality, the objective of this study is to highlight the scientific production about the nursing care process for post-surgical cardiac patients in Primary Health Care. This is an Integrative Literature Review, which seeks to deepen about the topic of interest, through analysis and synthesis of primary studies. The development of this study took place in five stages: formulation of the problem, literature search, data evaluation, data analysis and presentation. Regarding the results, it was found that patients affected by cardiovascular disea-ses and submitted to cardiac surgery, are subject to face
\end{abstract}


several changes in their lives, involving physical, emotional and psychosocial aspects. Finally, it was noticed that through relevant assistance techniques, such as therapeutic listening, and through the nurse's different view, understanding the patient as a broad and complex being, nursing care in Primary Health Care is presented differently, resulting in a positive application to the care process of this group of patients.

Keywords: Nursing process; Primary health care; Continuity of patient care; Thoracic surgery.

\section{Resumen}

Los pacientes crónicos que se han sometido a un procedimiento quirúrgico se encuentran en un período de fragilidad. Ante esto, el enfermero en Atención Primaria de Salud tiene un papel importante en el proceso de atención, ya que necesita tener habilidades para fortalecer al paciente, ayudándolo a enfrentar las dificultades relacionadas con su enfermedad, promovien-do su seguridad y autoconfianza. Siendo de la particularidad de este profesional, la mirada diferente del paciente, analizán-dolo como un ser biopsicosocial. A partir de esta realidad, el objetivo de este estudio es destacar la producción científica sobre el proceso de atención de enfermería al paciente cardíaco posquirúrgico en Atención Primaria de Salud. Se trata de una Revista Integrativa de la Literatura, que busca profundizar en el tema de interés, a través de análisis y síntesis de estudios primarios. El desarrollo de este estudio se llevó a cabo en cinco etapas: formulación del problema, búsqueda bibliográfica, evaluación de datos, análisis y presentación de datos. En cuanto a los resultados, se encontró que los pacientes afectados por enfermedades cardiovasculares y sometidos a cirugía cardíaca, están sujetos a enfrentar varios cambios en su vida, que involucran aspectos físicos, emocionales y psicosociales. Finalmente, se notó que a través de técnicas asistenciales relevan-tes, como la escucha terapéutica, y a través de la mirada diferente del enfermero, entendiendo al paciente como un ser am-plio y complejo, la atención de enfermería en la Atención Primaria de Salud se presenta de manera diferente, resultando en una aplicación positiva al paciente. proceso de atención de este grupo de pacientes.

Palabras clave: Proceso de enfermería; Atención primaria de salud; Continuidad de la atención al paciente; Cirugía torácica.

\section{Introdução}

As doenças crônicas não transmissíveis (DNT) são uma das maiores preocupações de saúde global, pois são responsáveis pela maior taxa de mortalidade mundial. Enquadram-se nesse contexto as doenças cardiovasculares, doenças respiratórias crônicas, diabetes mellitus e neoplasias. As DNT encontram-se entre as 10 principais causas de morte no mundo, apresentando como classificação: doença isquêmica do coração; doença cerebrovascular; infecções de vias aéreas inferiores; Alzheimer e outras demências; doença pulmonar obstrutiva crônica; violência interpessoal; diabetes mellitus; acidentes de trânsito; doença renal crônica; cirrose e outras doenças hepáticas crônicas. E são responsáveis por $71 \%$ das mortes globais, acometendo países de diferentes níveis econômicos, porém apresentando variações entre países de baixa renda (37\%) e alta renda (88\%). (Ministério da Saúde, 2017; World Health Organization, 2018).

As doenças cardiovasculares merecem destaque, pois representavam 32\% das mortes por DNT em 2005, e em 2016 permaneceram em primeiro lugar no ranking das principais causas de morte no mundo, representando taxa bruta de mortalidade de 126/100 000 habitantes, sendo até hoje consideradas a principal causa de morte no mundo. Destaca-se ainda, que conforme declaração da Organização Mundial de Saúde (OMS), as doenças cardiovasculares provocam a morte de cerca de 17,7 milhões de pessoas mundialmente. Esta realidade corresponde aproximadamente 31\% dos óbitos totais no mundo. (Organização Pan-Americana da Saúde, 2017; World Health Organization, 2019).

Dentre as doenças cardiovasculares encontramos: doença coronariana, doença cerebrovascular, doença arterial periférica, doença cardíaca reumática, cardiopatia congênita, trombose venosa profunda e embolia pulmonar. Essas podem apresentar fatores comportamentais de risco como sinais de alerta, como, elevação da pressão arterial (PA), hiperglicemia, hiperlipidemia, sobrepeso e obesidade. Quando presentes essas alterações, o acompanhamento pode ocorrer através da Atenção Primária à Saúde (APS), prevenindo assim a ocorrência de complicações mais graves como ataques cardíacos, insuficiência cardíaca, entre outras. (Organização Pan-Americana da Saúde, 2017).

As doenças cardíacas causam muitas limitações na qualidade de vida dos indivíduos, afetando aspectos físicos, sociais, da área financeira e da saúde. Essas enfermidades afetam a produtividade no ramo do serviço, além de custos referente a assistência à saúde. As principais doenças cardíacas que levam a intervenção cirúrgica são insuficiência Cardíaca (IC), 
Infarto do Miocárdio (IM), Fibrilação Arterial (FA) e Hipertensão Arterial Sistêmica (HAS), sendo a HAS a mais prevalente, seguida da IC. Essas doenças em conjunto afetam aproximadamente 45,7 milhões de pessoas no Brasil (32\% da população adulta), com custo financeiro de $\mathrm{R} \$ 56,2$ bilhões em 2015 , correspondendo a cerca de 5,5\% do total da despesa nacional com assistência à saúde. (Stevens et al., 2018).

Referente as intervenções cirúrgicas, compreende-se que durante todas as fases do processo cirúrgico (pré, trans e pós-operatório) existe a possibilidade de ocorrer complicações de diferentes gravidades ao paciente. Dentre estas alterações, destacamos as que obtêm maior prevalência entre os pacientes pós-cirúrgicos, são elas: complicações cardíacas, pulmonares, cerebrovasculares, neurológicas, infecciosas e renais. No pós-operatório, imediato ou mediado, especificamente, é necessário que haja uma assistência adequada para proporcionar uma ideal recuperação ao paciente, através de cuidados definidos para cada caso clínico. Quando não ocorre a devida execução destes cuidados, podemos nos deparar com alterações clínicas que comprometam à saúde, e em alguns casos, a vida do indivíduo. É válido relembrar que a recuperação do paciente pós-cirúrgico nem sempre é definida por fatores isolados, mas sim por diversos fatores associados, como: histórico do paciente, histórico clínico e cuidados pré, intra e pós-operatórios. (Soares et al., 2011).

As principais complicações pós-operatórias que afetam pacientes pós-cirúrgicos de cirurgias cardiovasculares, são as complicações cardíacas, pulmonares, renais, neurológicas, infecciosas, hematológicas, digestivas e distúrbios hidroeletrolíticos. Sendo dessas, com maior prevalência as complicações pulmonares, cardíacas e neurológicas, respectivamente. As complicações cardíacas, especificamente síndrome do baixo débito cardíaco, foram verificadas como complicação com maior destaque na mortalidade hospitalar. (Soares et al., 2011).

Em 1988 houve a criação do SUS, através da Constituição Federal de 1988 art. 196 que decreta que a "a saúde é direito de todos e dever do Estado". (Brasil, 1988, p.1). O programa é desenvolvido por meio de três princípios básicos: universalidade, equidade e integralidade, ou seja, a garantia do acesso integral, universal e gratuito à saúde para toda a população brasileira, proporcionando um atendimento específico para as necessidades de cada paciente em sua individualidade. Dentro do SUS encontramos ramificações de atendimento à população, que são: atenção primária, serviços de média e de alta complexidade, serviços urgência e emergência, atenção hospitalar, ações e serviços das vigilâncias epidemiológica, sanitária e ambiental e assistência farmacêutica. Por meio da gestão e responsabilidade dos poderes da União, Estados e Municípios. Dentro dos diferentes serviços disponibilizados, possuímos como interesse a visualização do atendimento na Atenção Básica à Saúde, que é vista como a principal porta de entrada dos usuários para o atendimento ao SUS. Pois através das Unidades de Saúde, proporciona que os usuários tenham um atendimento amplo, adequado, acessível e que seja próximo de suas residências. (Ministério da Saúde, 2012; Ministério da Saúde, 2020).

Na Atenção Primária, além das responsabilidades gerenciais, também compete ao enfermeiro a prestação de cuidados englobando as especificidades de cada paciente. Os pacientes com presença e/ou histórico de doenças cardíacas, necessitam de cuidados específicos para sua patologia. O enfermeiro na Atenção Primária necessita dispor de métodos que visem a prevenção, tratamentos e cuidados ao paciente cardíaco, medidas essas que podem ser aplicadas através das consultas de enfermagem. As atividades desenvolvidas pelo enfermeiro devem direcionar-se ao processo de cuidar, através da interação entre o profissional e o paciente, buscando a implementação de cuidados 'para' e 'com' o indivíduo atendido. Este processo de cuidar deve basear-se em alguns aspectos como o conhecimento científico, habilidade, raciocínio crítico e clínico, intuição, criatividade e assistência cuidativa, buscando a promoção, manutenção, e/ou recuperação do paciente e do seu estado de saúde. (Balduino et al., 2009).

Por meio das consultas diárias, ao enfermeiro compete a particularidade do olhar diferenciado ao paciente, analisando aspectos objetivos e subjetivos, e realizando o encaminhamento deste paciente para atendimentos assistenciais adequados à sua necessidade. O paciente crônico necessita de cuidados planejados, a fim de suprir suas necessidades e fornecer atendimento 
integrado e integral. Para isso, é importante que haja treinamento com o paciente e família, a fim de ensiná-los a implementar o processo do cuidado em suas residências, fornecendo todo suporte e apoio necessário. (Balduino et al., 2009).

Também devem ser avaliadas em pacientes com alterações cardiovasculares e que passaram por algum procedimento cirúrgico, a incidência de ansiedade, depressão e avaliação da qualidade de vida do usuário após o procedimento cardíaco. Com o passar dos anos a avaliação psicológica dos pacientes vem sendo tratada de forma mais persistente, isto pode se dar pelo fato da alta incidência de transtornos mentais ao longo dos anos. Os pacientes que passaram por cirurgias cardíacas, apresentam grande tendência para desenvolvimento de manifestações psicológicas como ansiedade, depressão e estresse, pois foram submetidos a um evento traumático, bem como pacientes que enfrentam doenças crônicas. (Organização Pan-Americana da Saúde, 2018).

O desempenho e qualidade de vida dos pacientes é um fator determinante para a manutenção da saúde do indivíduo. Pacientes que passam por um procedimento cirúrgico cardíaco tendem a apresentar sentimentos de temor, preocupação, tristeza, depressão e alterações no padrão de sono. Sendo as mudanças no padrão do sono, diretamente ligadas a alterações endócrinas, metabólicas, físicas, cognitivas e neurais, comprometendo assim, a saúde e qualidade de vida do indivíduo. Muitas vezes os pacientes podem estar buscando um meio para eliminar suas inseguranças e adquirir afeto e atenção durante as consultas nas Unidades de Saúde, por isso se faz necessário que os profissionais de saúde disponham de seu tempo para implementar formas de suprir as necessidades apresentadas pelos pacientes. Neste aspecto encontramos a escuta terapêutica, que é uma técnica que acarreta resultados positivos referente ao cuidado ao usuário. (Galter et al., 2010; Lima et al., 2015).

Durante as consultas de enfermagem, o relacionamento entre profissional e paciente é construído e fortificado, sendo essa uma das grandes vantagens encontradas na APS. Neste tipo de atendimento, conforme o andamento das consultas, começa a ser estabelecido um vínculo entre o paciente e o profissional. E este vínculo proporciona que o paciente consiga se expressar e discutir assuntos particulares com o profissional, possibilitando que o atendimento seja cada vez mais específico para suas condições, através do aumento da confiança e relação entre os envolvidos. A escuta terapêutica visa o acolhimento ao paciente, escutando tudo o que ele está disposto a relatar e coletando o máximo de informações possíveis. É um momento indispensável e que serve para acolher e conquistar a confiança do indivíduo, além de contribuir para as intervenções frente a sua patologia. (Lima et al., 2015).

O interesse pela temática surgiu ao longo da graduação, intensificando-se ao imergir no grupo de pesquisa Laboratório de Estudos de Processos Socioambientais e Produção de Saúde (LAMSA), onde houve o contato com a dissertação de Mestrado de uma integrante do grupo referente ao acompanhamento dos pacientes com alterações cardiovasculares na Unidade hospitalar. Desta forma, surgiu a curiosidade técnica e científica de explorar o acompanhamento realizado pela enfermagem na APS, aos pacientes submetidos a cirurgia cardiovascular. Pensando nisso, temos como objetivo nesta revisão integrativa de literatura, evidenciar a produção científica acerca do processo cuidativo de enfermagem ao paciente cardíaco pós-cirúrgico na Atenção Primária à Saúde.

\section{Metodologia}

\subsection{Tipo de estudo}

Este estudo trata-se de uma Revisão Integrativa de Literatura (RI). Seu principal objetivo é o aprofundamento acerca da temática de interesse, por meio de análise e síntese de estudos primários. É considerado um método específico que reúne dados empíricos ou teóricos, a fim de possibilitar o entendimento extensivo referente a um determinado tema. Possibilita uma análise abrangente da literatura, e assim, o desenvolvimento de discussões e reflexões dos resultados obtidos. Na RI, os dados são resumidos e comparados, permitindo o desenvolvimento de conclusões referentes à questão de pesquisa. É de extrema importância que os padrões metodológicos sejam seguidos com rigidez, para que assim, os dados fornecidos sejam de alta 
credibilidade. (Whittemore \& Knafl, 2005; Crossetti, 2012).

\subsection{Fases da Revisão Integrativa de Literatura}

Uma revisão integrativa bem conduzida, proporciona qualidade nos resultados apresentados, e permite a identificação de questões que necessitam de maior aprofundamento na produção científica. Então, para o desenvolvimento de uma RI, é necessário que sejam seguidas cinco etapas, são elas: formulação do problema; pesquisa de literatura; avaliação dos dados; análise dos dados, e apresentação dos resultados. (Whittemore \& Knafl, 2005).

\subsubsection{Identificação do problema e formulação da questão de pesquisa}

A primeira etapa da revisão integrativa iniciou com a identificação do problema e posteriormente, desenvolvimento da questão de pesquisa. Foi necessário clareza no objetivo da revisão, e relevância da questão de pesquisa para a área da saúde e enfermagem. (Whittemore \& Knafl, 2005; Souza et al., 2010).

Para o desenvolvimento da questão de pesquisa foram analisados alguns itens, como: o objetivo deste estudo e embasamento e aprofundamento teórico por meio das bases de dados eletrônicas e conteúdos disponibilizados pelo Ministério da Saúde e Organização Pan-Americana da Saúde. Após o aprofundamento na literatura, houve a formulação da questão norteadora, para direcionar a busca de estudos que atendessem ao objetivo da pesquisa, definida como: "Quais as evidências científicas disponíveis na literatura acerca do processo cuidativo de enfermagem ao paciente cardíaco pós-cirúrgico na Atenção Primária à Saúde?”

\subsubsection{Pesquisa na literatura}

Etapa caracterizada pela coleta dos dados nas bases de dados, buscando a obtenção de estudos para compor a revisão integrativa de literatura. Também foram informadas as bases de dados eletrônicas e descritores que foram utilizados. Nesta etapa foram utilizados os operadores booleanos (AND e OR), para combinação dos termos e localização dos estudos. Esses operadores representam uma combinação de termos restritiva e aditiva, respectivamente. (Whittemore \& Knafl, 2005).

Foram aplicados os critérios de elegibilidade, para determinação dos estudos utilizados na revisão. Neste momento os estudos foram avaliados, aplicando os critérios de inclusão e exclusão da revisão. A aplicação dos critérios de elegibilidade tem o objetivo de encontrar os estudos que respondam à pergunta da revisão, através de uma associação dos itens importantes da questão de pesquisa e especificações relacionadas. (Whittemore \& Knafl, 2005).

A busca dos estudos foi na produção da área da Enfermagem, com ênfase no trabalho/acompanhamento desenvolvido pelo Enfermeiro. Para localização e seleção dos estudos, foi realizada a busca nas seguintes bases de dados: US National Library of Medicine (PubMed), Biblioteca Virtual em Saúde (BVS), e Scientific Eletronic Library Online (SciELO). Esta etapa se desenvolveu no mês de outubro de 2020, tendo como descritores: Processo de Enfermagem (Nursing Process); Atenção Primária à Saúde (Primary Health Care); Continuidade da Assistência ao Paciente (Continuity of Patient Care); e Cirurgia Torácica (Thoracic surgery). Os descritores, verificados na lista dos Descritores das Ciências da Saúde (DeCS), foram aplicados nos idiomas português e inglês, e combinados de diferentes formas sendo separados pelos operadores boleanos AND e OR, para garantir uma ampla e completa busca de dados.

Para a seleção dos estudos, foram utilizados como critérios de inclusão para esta revisão integrativa de literatura: estudos científicos, publicados entre o período de 2010 a 2020, disponíveis em português, disponíveis online em sua totalidade e que respondessem à questão norteadora. Foram excluídos desta revisão, os artigos com as seguintes especificações: estudos não primários, duplicados, indisponíveis na íntegra e artigos que tenham estudado participantes diferentes dos propostos na questão de pesquisa. 


\subsubsection{Avaliação dos dados}

A partir dos critérios estabelecidos na etapa anterior, foi realizada uma avaliação dos dados obtidos, verificando se eram estudos qualificados para a temática da pesquisa, ou seja, que atenderam a questão de pesquisa. Para a avaliação dos dados, foi realizado leitura minuciosa dos estudos, em sua totalidade.

\subsubsection{Análise dos dados}

Esta fase caracteriza-se pela extração dos dados e distribuição em categorias sistemáticas, por meio de um método de comparação. Os dados de pesquisas primárias foram ordenados, codificados, categorizados e somados em uma análise unificada do problema da pesquisa. Foi realizada a aplicação deste método, que consiste em: redução de dados, exibição de dados, comparação de dados, desenho de conclusão e verificação. (Whittemore \& Knafl, 2005).

Redução dos dados: fase em que ocorreu a divisão, em subgrupos, das fontes primárias incluídas na RI. Para a redução dos dados, foi empregado um sistema de classificação geral, a fim de gerenciar as evidências obtidas pelas diferentes metodologias. O objetivo desta etapa é de simplificar e organizar os dados de uma forma gerenciável. Cada fonte primária, foi resumida com os dados similares.

As subdivisões foram baseadas em diferentes elementos, como: os tipos de estudos encontrados, cronologia, meio de aplicação do estudo, característica dos participantes, comportamento dos participantes, ou seja, a classificação de cada subgrupo foi realizada com base nas evidências encontradas, sendo posteriormente, analisadas de forma sequencial. Esta etapa serviu para direcionamento e análise dos autores.

Exibição de dados: etapa onde os estudos primários foram exibidos em formato tabular. Com o objetivo de proporcionar melhora na visualização dos padrões e relações dos dados, servindo assim, como ponto inicial para a interpretação dos dados.

Comparação de dados: momento em que ocorreu a análise comparativa dos dados de fonte primária, com o objetivo de encontrar padrões, temas e aspectos semelhantes ou discrepantes.

Desenho de conclusão e verificação: realização da fase final da análise, onde foi realizado um desenho da conclusão e verificação. A finalização da análise foi realizada com extremo cuidado, evitando fechamento analítico prematuro ou a exclusão de dados importantes para a finalização do estudo.

$\mathrm{Na}$ análise de conteúdo, foi desenvolvida uma tabela apresentando as características dos estudos selecionados para a revisão, os dados foram distribuídos para realização do comparativo, esse instrumento inclui: número do estudo; título do estudo; autores; método utilizado; objetivos; resultados e principais conclusões. Também foi desenvolvida outra tabela, apresentando em forma de porcentagem, as variáveis encontradas nos artigos científicos utilizados nesta revisão, sendo elas: local da realização da pesquisa, ano de publicação, periódico de publicação dos artigos, participantes do estudo, e abordagem de cada artigo (qualitativa, quantitativa ou mista).

\subsubsection{Apresentação}

A última etapa foi realizada de forma descritiva, após profunda análise e interpretação dos estudos incluídos na RI. Foram apresentados os principais resultados, as implicações e limitações da pesquisa. Por fim, houve a discussão das evidências obtidas para uma eficiente conclusão do tema abordado.

\subsection{Aspectos éticos}

Foi dispensado o envio do estudo ao Comitê de Ética em Pesquisa (CEP/FURG), por se tratar de uma Revisão Integrativa de Literatura, "pesquisa que utilize informações de acesso público", conforme as diretrizes e normas estabelecidas 
na RESOLUÇÃO N 510, DE 07 DE ABRIL DE 2016, do Conselho Nacional de Saúde. (Resolução nº 510, 2016).

\section{Resultados e Discussão}

Por meio da pesquisa de literatura, foram encontrados 5.245 estudos referentes ao tema, sendo 3.497 indexados na Pubmed, 1.286 na BVS e 462 na Scielo. Do total de artigos encontrados, foram excluídos 2.341 por se tratar de artigos duplicados mais de uma vez. Após, houve leitura detalhada dos títulos e resumos dos 2.904 estudos restantes, sendo excluídos 2.794. Com isso, os 110 estudos foram selecionados para leitura na íntegra, sendo excluídos 99 por não atenderem aos critérios de elegibilidade e por fim, restaram 11 artigos que foram incluídos nesta revisão integrativa. Estas informações podem ser analisadas na Figura 1.

Figura 1. Fluxograma da informação com as diferentes fases da revisão integrativa.
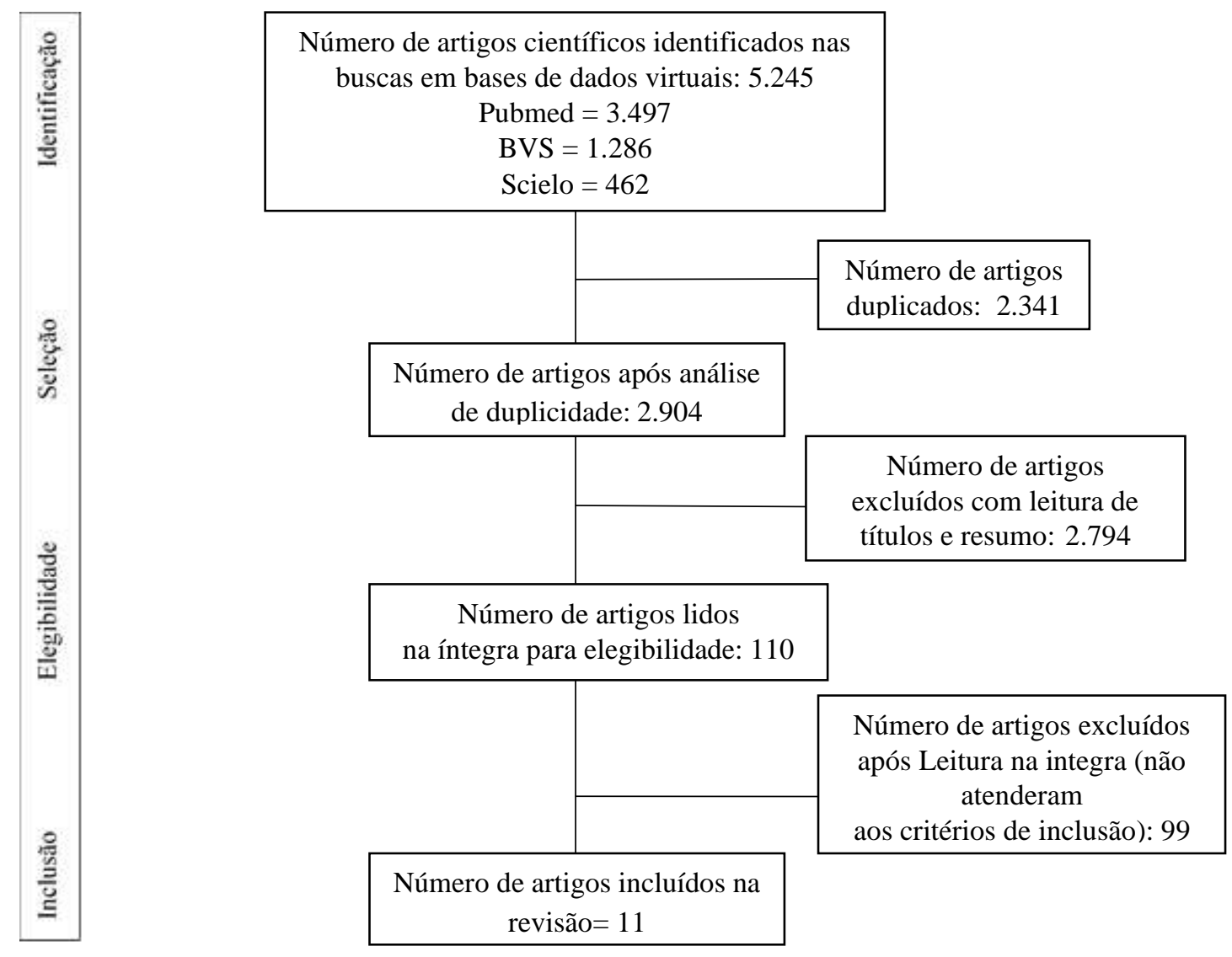

Fonte: Autores, a partir de dados disponíveis em Galvão et al. (2015).

Foi possível identificar uma baixa produção científica referente ao tema. Com isso, percebemos que grande parte dos pacientes que foram submetidos a intervenção cirúrgica cardiovascular, não possuem uma continuidade da assistência na APS, local este que possui grande potencial para monitoramento dos pacientes que vivem na comunidade.

Desenvolvemos um quadro (Quadro 1), organizado de forma alfabética de acordo com o título do estudo, para caracterização dos artigos, a fim de possibilitar uma análise prática e clara dos estudos selecionados para esta revisão integrativa. Este quadro contém os seguintes itens: número do estudo, título do estudo, autores, método utilizado, objetivos, resultados e principais conclusões. 
Quadro 1. Caracterização dos artigos científicos utilizados nesta revisão.

\begin{tabular}{|c|c|c|c|c|c|c|}
\hline $\mathbf{N}^{\mathbf{o}}$ & Título & Autores & Método & Objetivos & Resultados & $\begin{array}{l}\text { Principais } \\
\text { conclusões }\end{array}$ \\
\hline 1 & $\begin{array}{l}\text { Encaminha } \\
\text { mento e } \\
\text { contrarrefer } \\
\text { ência: } \\
\text { repercussõe } \\
\text { s da } \\
\text { cirurgia de } \\
\text { revasculari } \\
\text { zação do } \\
\text { miocárdio } \\
\text { na } \\
\text { perspectiva } \\
\text { da Atenção } \\
\text { Básica }\end{array}$ & $\begin{array}{l}\text { Kahl, C.; } \\
\text { Cunha, K. } \\
\text { S. da; } \\
\text { Lanzoni, } \\
\text { G. M. de } \\
\text { M.; } \\
\text { Higashi, G. } \\
\text { D. C.; } \\
\text { Erdmann, } \\
\text { A. L.; } \\
\text { Baggio, M. } \\
\text { A. }\end{array}$ & $\begin{array}{c}\text { Pesquisa } \\
\text { qualitativa } \\
\text { com } \\
\text { contribuição } \\
\text { teórico- } \\
\text { metodológica } \\
\text { ancorada na } \\
\text { Teoria } \\
\text { Fundamentada } \\
\text { nos Dados }\end{array}$ & $\begin{array}{l}\text { Compreender as } \\
\text { repercussões do } \\
\text { encaminhamento e } \\
\text { contrarreferência } \\
\text { de pacientes com } \\
\text { indicação / } \\
\text { submetidos à } \\
\text { cirurgia de } \\
\text { revascularização } \\
\text { do miocárdio no } \\
\text { contexto da } \\
\text { Atenção Básica à } \\
\text { Saúde. }\end{array}$ & $\begin{array}{l}\text { A necessidade de } \\
\text { melhoria no processo de } \\
\text { registro dos dados } \\
\text { clínicos no sistema de } \\
\text { regulação surgiu para } \\
\text { fortalecer o } \\
\text { encaminhamento do } \\
\text { paciente; e a ausência de } \\
\text { um processo formal de } \\
\text { contrarreferência e } \\
\text { adaptação do estilo de } \\
\text { vida com repercussão na } \\
\text { contrarreferência. }\end{array}$ & $\begin{array}{l}\text { As repercussões do } \\
\text { encaminhamento e } \\
\text { contrarreferência de } \\
\text { pacientes com } \\
\text { indicação / } \\
\text { submetidos à CRM no } \\
\text { contexto da Atenção } \\
\text { Básica são } \\
\text { vivenciadas por meio } \\
\text { da orientação } \\
\text { profissional e, em } \\
\text { especial, do apoio } \\
\text { familiar. }\end{array}$ \\
\hline 2 & $\begin{array}{c}\text { Enfermeira } \\
\text { de ligação: } \\
\text { estratégia } \\
\text { de } \\
\text { integração } \\
\text { entre } \\
\text { Hospital e } \\
\text { unidades } \\
\text { da atenção } \\
\text { primária }\end{array}$ & $\begin{array}{l}\text { RIBAS, E. } \\
\text { do N. }\end{array}$ & $\begin{array}{c}\text { Pesquisa de } \\
\text { intervenção de } \\
\text { caráter } \\
\text { exploratório e } \\
\text { de abordagem } \\
\text { qualitativa. }\end{array}$ & $\begin{array}{c}\text { Propor estratégia } \\
\text { de } \\
\text { contrarreferência } \\
\text { do hospital para a } \\
\text { atenção } \\
\text { primária com a } \\
\text { contribuição da } \\
\text { "enfermeira de } \\
\text { ligação"; avaliar o } \\
\text { projeto piloto da } \\
\text { “enfermeira de } \\
\text { ligação" na } \\
\text { perspectiva das } \\
\text { enfermeiras das } \\
\text { unidades de } \\
\text { internação } \\
\text { do hospital e da } \\
\text { UPA que } \\
\text { realizaram a } \\
\text { contrarreferência; } \\
\text { avaliar a proposta } \\
\text { na } \\
\text { perspectiva das } \\
\text { enfermeiras da } \\
\text { atenção primária e } \\
\text { identificar o } \\
\text { perfil dos usuários } \\
\text { encaminhados das } \\
\text { unidades de } \\
\text { internação do } \\
\text { hospital e da UPA } \\
\text { saúde. }\end{array}$ & $\begin{array}{c}\text { Em relação aos } \\
\text { enfermeiros que } \\
\text { realizaram a } \\
\text { contrarreferência foi } \\
\text { identificado quatro } \\
\text { categorias: dificuldades } \\
\text { relacionadas aos } \\
\text { usuários, dificuldades } \\
\text { relacionadas ao processo } \\
\text { de trabalho, facilidades e } \\
\text { sugestões. Em relação } \\
\text { aos enfermeiros que } \\
\text { receberam os usuários na } \\
\text { atenção primária foram } \\
\text { identificados seis } \\
\text { categorias: Opinião sobre } \\
\text { o projeto, contato por } \\
\text { telefone, informações } \\
\text { recebidas sobre } \\
\text { o usuário, recebimento } \\
\text { da documentação de alta } \\
\text { via e-mail, inclusão desta } \\
\text { função no } \\
\text { processo de trabalho do } \\
\text { enfermeiro e sugestões. }\end{array}$ & $\begin{array}{c}\text { Todos os enfermeiros } \\
\text { consideraram } \\
\text { importante a } \\
\text { realização da } \\
\text { contrarreferência e } \\
\text { que este processo } \\
\text { impactou diretamente } \\
\text { na qualidade do } \\
\text { atendimento, sendo } \\
\text { possível ser } \\
\text { implantado. }\end{array}$ \\
\hline 3 & $\begin{array}{c}\text { Enfermeira } \\
\text { de ligação: } \\
\text { uma } \\
\text { estratégia } \\
\text { para a } \\
\text { contrarrefer } \\
\text { ência }\end{array}$ & $\begin{array}{l}\text { Ribas, E. } \\
\text { do N.; } \\
\text { Bernardino } \\
\text {, E.; } \\
\text { Larocca, L. } \\
\text { M.; Neto, } \\
\text { P. P.; } \\
\text { Aued, G. }\end{array}$ & $\begin{array}{l}\text { Pesquisa de } \\
\text { intervenção, } \\
\text { com doze } \\
\text { enfermeiras } \\
\text { assistenciais } \\
\text { de um hospital } \\
\text { e de uma } \\
\text { Unidade }\end{array}$ & $\begin{array}{l}\text { Identificar o perfil } \\
\text { dos usuários } \\
\text { contrarreferenciad } \\
\text { os pela } \\
\text { "enfermeira de } \\
\text { ligação" e } \\
\text { descrever a } \\
\text { experiência das }\end{array}$ & $\begin{array}{c}\text { Dentre os aspectos } \\
\text { positivos, as enfermeiras } \\
\text { destacaram o diálogo } \\
\text { entre os pontos de } \\
\text { atenção, agilidade } \\
\text { na aquisição de insumos } \\
\text { para a continuidade dos } \\
\text { cuidados na atenção }\end{array}$ & $\begin{array}{c}\text { A “enfermeira de } \\
\text { ligação" } \\
\text { mostrou-se uma } \\
\text { importante estratégia } \\
\text { para melhorar a } \\
\text { integração entre os } \\
\text { serviços e promover a } \\
\text { continuidade do }\end{array}$ \\
\hline
\end{tabular}




\begin{tabular}{|c|c|c|c|c|c|c|}
\hline & & $\begin{array}{l}\text { K.; Silva, } \\
\text { C. P. C. da }\end{array}$ & $\begin{array}{c}\text { de Pronto } \\
\text { Atendimento, } \\
\text { e } 26 \\
\text { enfermeiras da } \\
\text { Atenção } \\
\text { Primária à } \\
\text { Saúde. }\end{array}$ & $\begin{array}{c}\text { profissionais } \\
\text { que participaram } \\
\text { do projeto. }\end{array}$ & $\begin{array}{l}\text { primária, beneficiando os } \\
\text { usuários após a alta } \\
\text { hospitalar. O maior } \\
\text { desafio foi a carência de } \\
\text { tempo e o déficit de } \\
\text { enfermeiras para realizar } \\
\text { a função. }\end{array}$ & cuidado. \\
\hline 4 & $\begin{array}{l}\text { Paciente } \\
\text { cardíaco } \\
\text { revasculari } \\
\text { zado: } \\
\text { processo de } \\
\text { referência e } \\
\text { contra } \\
\text { referência } \\
\text { dos } \\
\text { serviços de } \\
\text { saúde de } \\
\text { Santa } \\
\text { Catarina }\end{array}$ & $\begin{array}{l}\text { Erdamann, } \\
\text { A. L.; } \\
\text { Meirelles, } \\
\text { B. H. S.; } \\
\text { Lanzoni, } \\
\text { G. M. de } \\
\text { M.; } \\
\text { Baggio, M. } \\
\text { A.; } \\
\text { Higashi, G. } \\
\text { D. C.; } \\
\text { Koerich, } \\
\text { C.; Cunha, } \\
\text { K. S. da; } \\
\text { Kahl, C. }\end{array}$ & $\begin{array}{c}\text { Pesquisa } \\
\text { quanti- } \\
\text { qualitativa, } \\
\text { organizada em } \\
\text { dois } \\
\text { momentos } \\
\text { concomitantes } \\
\text {. O primeiro } \\
\text { foi } \\
\text { quantitativo, } \\
\text { do tipo } \\
\text { epidemiológic } \\
\text { o } \\
\text { observacional } \\
\text { transversal, na } \\
\text { etapa } \\
\text { qualitativa, foi } \\
\text { realizada a } \\
\text { Teoria } \\
\text { Fundamentada } \\
\text { nos Dados. }\end{array}$ & $\begin{array}{l}\text { Compreender o } \\
\text { processo de } \\
\text { referência e } \\
\text { contrarreferência } \\
\text { da pessoa } \\
\text { acometida por } \\
\text { coronariopatia e } \\
\text { submetida à } \\
\text { revascularização } \\
\text { cardíaca nos } \\
\text { serviços de saúde } \\
\text { de Santa Catarina e } \\
\text { a interface com a } \\
\text { atuação do } \\
\text { enfermeiro. }\end{array}$ & $\begin{array}{c}\text { Instrumentos de } \\
\text { Regulação representam } \\
\text { importante meio para } \\
\text { integração dos serviços } \\
\text { de saúde, embora a } \\
\text { contrarreferência não } \\
\text { esteja estruturada. } \\
\text { Profissionais de saúde, } \\
\text { incluindo Enfermeiros, } \\
\text { apresentam } \\
\text { baixa resolutividade na } \\
\text { prática clínica na } \\
\text { Atenção Básica. }\end{array}$ & $\begin{array}{c}\text { Evidenciam-se } \\
\text { fragilidades no } \\
\text { processo de referência } \\
\text { e con- } \\
\text { trarreferência, com } \\
\text { desarticulação entre } \\
\text { os diferentes pontos } \\
\text { da rede de atenção à } \\
\text { saúde e necessidade } \\
\text { de fortalecimento das } \\
\text { estratégias eficientes } \\
\text { para garantir acesso e } \\
\text { cuidado seguro, com } \\
\text { vínculo entre os } \\
\text { profissionais } \\
\text { da Atenção Básica e } \\
\text { usuário. }\end{array}$ \\
\hline 5 & $\begin{array}{c}\text { Qualidade } \\
\text { de vida de } \\
\text { mulheres } \\
\text { submetidas } \\
\text { à } \\
\text { Cirurgia de } \\
\text { revasculari } \\
\text { zação do } \\
\text { miocárdio } \\
\text { Em um } \\
\text { hospital } \\
\text { público }\end{array}$ & $\begin{array}{l}\text { Oliveira, } \\
\text { R. M. de; } \\
\text { Sena, Z. } \\
\text { G. F. de; } \\
\text { Frota, } \\
\text { L. M. da } \\
\text { C. P.; } \\
\text { Oliveira, } \\
\text { J. B. B. de }\end{array}$ & $\begin{array}{c}\text { Estudo } \\
\text { qualitativo } \\
\text { através da } \\
\text { aplicação de } \\
\text { um formulário } \\
\text { sobre estilo de } \\
\text { vida e fatores } \\
\text { de risco } \\
\text { e de uma } \\
\text { entrevista } \\
\text { contendo } \\
\text { quatro } \\
\text { perguntas } \\
\text { norteadoras. }\end{array}$ & $\begin{array}{l}\text { Analisar o perfil } \\
\text { sociodemográfico, } \\
\text { fatores de risco e a } \\
\text { qualidade de vida } \\
\text { de } \\
\text { mulheres } \\
\text { submetidas à } \\
\text { cirurgia de } \\
\text { revascularização } \\
\text { do miocárdio. }\end{array}$ & $\begin{array}{c}\text { O perfil das } \\
\text { pesquisadas mostrou que } \\
9(60 \%) \text { eram pardas, } 8 \\
(54 \%) \text { possuíam o ensino } \\
\text { fundamental } \\
\text { incompleto, } 4(27 \%) \\
\text { eram donas de casa, } 9 \\
(60 \%) \text { residiam em } \\
\text { perímetro urbano, } 10 \\
\text { (67\%) } \\
\text { eram casadas, todas } \\
\text { tinham renda familiar } \\
\text { abaixo de três salários } \\
\text { mínimos e } 4 \text { (27\%) } \\
\text { tinham } \\
\text { apenas dois filhos. A } \\
\text { partir da análise do } \\
\text { conteúdo das entrevistas, } \\
\text { emergiram as seguintes } \\
\text { categorias: religiosidade, } \\
\text { ruptura com o cotidiano, } \\
\text { família e qualidade de } \\
\text { vida. }\end{array}$ & $\begin{array}{l}\text { O conhecimento a } \\
\text { respeito da estrutura } \\
\text { psicossocial de cada } \\
\text { paciente ajuda no } \\
\text { tratamento do } \\
\text { indivíduo submetido à } \\
\text { cirurgia de } \\
\text { revascularização do } \\
\text { miocárdio. Ao } \\
\text { identificar o estilo de } \\
\text { vida e os fatores de } \\
\text { risco, as mulheres } \\
\text { promovem o } \\
\text { autoconhecimento, o } \\
\text { que poderá evitar } \\
\text { hábitos que levem ao } \\
\text { aparecimento de } \\
\text { doenças } \\
\text { cardiovasculares. } \\
\text { Sugere-se a } \\
\text { elaboração de } \\
\text { estratégias de } \\
\text { prevenção e } \\
\text { promoção de saúde } \\
\text { que envolvam as } \\
\text { pacientes e seus } \\
\text { familiares para que } \\
\text { haja uma extensão } \\
\text { dos cuidados } \\
\text { hospitalares em casa e } \\
\text { uma melhor } \\
\text { adaptação à nova }\end{array}$ \\
\hline
\end{tabular}




\begin{tabular}{|c|c|c|c|c|c|c|}
\hline & & & & & & condição clínica. \\
\hline 6 & $\begin{array}{l}\text { Referência } \\
\text { e } \\
\text { contrarrefer } \\
\text { ência: } \\
\text { repercussõe } \\
\text { s da } \\
\text { revasculari } \\
\text { zação } \\
\text { miocárdica } \\
\text { na } \\
\text { perspectiva } \\
\text { da Atenção } \\
\text { Primária }\end{array}$ & $\begin{array}{l}\text { Kahl, C; } \\
\text { Cunha, K. } \\
\text { S. da; } \\
\text { Lanzoni, } \\
\text { G. M. de } \\
\text { M; } \\
\text { Higashi, G. } \\
\text { D. C.; } \\
\text { Erdmann, } \\
\text { A. L.; } \\
\text { Baggio, M. } \\
\text { A. }\end{array}$ & $\begin{array}{l}\text { Pesquisa } \\
\text { qualitativa } \\
\text { com aporte } \\
\text { teórico- } \\
\text { metodológico } \\
\text { ancorado na } \\
\text { Teoria } \\
\text { Fundamentada } \\
\text { nos Dados. }\end{array}$ & $\begin{array}{l}\text { Compreender } \\
\text { como são } \\
\text { vivenciadas as } \\
\text { repercussões do } \\
\text { processo de } \\
\text { referência e } \\
\text { contrarreferência } \\
\text { do paciente com } \\
\text { indicação/submetid } \\
\text { o à Cirurgia de } \\
\text { Revascularização } \\
\text { Miocárdica na } \\
\text { Atenção Primária à } \\
\text { Saúde. }\end{array}$ & $\begin{array}{l}\text { Emergiu a necessidade } \\
\text { de melhoria no processo } \\
\text { de registro dos dados } \\
\text { clínicos no sistema de } \\
\text { regulação para } \\
\text { fortalecimento da } \\
\text { referência do paciente; e } \\
\text { ausência de um processo } \\
\text { formal de } \\
\text { contrarreferência e } \\
\text { adaptação do estilo de } \\
\text { vida com repercussão na } \\
\text { contrarreferência. }\end{array}$ & $\begin{array}{c}\text { As repercussões do } \\
\text { processo de referência } \\
\text { e contrarreferência do } \\
\text { paciente com } \\
\text { indicação/submetido à } \\
\text { CRM no contexto da } \\
\text { Atenção Primária são } \\
\text { vivenciadas por meio } \\
\text { das orientações } \\
\text { profissionais e, em } \\
\text { especial, pelo apoio } \\
\text { da família. }\end{array}$ \\
\hline 7 & $\begin{array}{l}\text { Revasculari } \\
\text { zação do } \\
\text { miocárdio: } \\
\text { fatores } \\
\text { intervenien } \\
\text { tes na } \\
\text { referência e } \\
\text { contra- } \\
\text { referência } \\
\text { no } \\
\text { ambiente } \\
\text { hospitalar }\end{array}$ & $\begin{array}{l}\text { Cunha, K. } \\
\text { S. da; } \\
\text { Kahl, C; } \\
\text { Koerich, } \\
\text { C.; } \\
\text { Lanzoni, } \\
\text { G. M. de } \\
\text { M; } \\
\text { Erdmann, } \\
\text { A. L.; } \\
\text { Meirelles, } \\
\text { B. H. S. }\end{array}$ & $\begin{array}{c}\text { Pesquisa } \\
\text { ancorada na } \\
\text { Teoria } \\
\text { Fundamentada } \\
\text { nos Dados } \\
\text { (Teoria } \\
\text { Fundamentada } \\
\text { nos Dados). }\end{array}$ & $\begin{array}{l}\text { Compreender os } \\
\text { fatores } \\
\text { intervenientes no } \\
\text { processo de } \\
\text { referência e } \\
\text { contrarreferência } \\
\text { da pessoa com } \\
\text { doença cardíaca no } \\
\text { cenário de alta } \\
\text { complexidade da } \\
\text { rede de atenção à } \\
\text { saúde. }\end{array}$ & $\begin{array}{l}\text { Os fatores intervenientes } \\
\text { no processo de referência } \\
\text { foram a dificuldade de } \\
\text { acesso aos pontos da } \\
\text { rede e telemedicina e a } \\
\text { central para gerir o fluxo } \\
\text { de pacientes na rede. Na } \\
\text { contrarreferência, havia } \\
\text { vínculo com o hospital e } \\
\text { falta de comunicação } \\
\text { entre os profissionais da } \\
\text { rede. }\end{array}$ & $\begin{array}{l}\text { Revela a necessidade } \\
\text { de reorganizar o fluxo } \\
\text { de atendimento no } \\
\text { RAS, potencializando } \\
\text { a APS, ampliando a } \\
\text { atuação da média } \\
\text { complexidade e } \\
\text { aumentando a } \\
\text { capacidade da alta } \\
\text { complexidade para } \\
\text { realizar o processo de } \\
\text { referência e } \\
\text { contrarreferência. }\end{array}$ \\
\hline 8 & $\begin{array}{l}\text { Revasculari } \\
\text { zação } \\
\text { miocárdica: } \\
\text { fatores } \\
\text { interventor } \\
\text { es na } \\
\text { referência e } \\
\text { contrarrefer } \\
\text { ência na } \\
\text { Atenção } \\
\text { Primária à } \\
\text { Saúde }\end{array}$ & $\begin{array}{l}\text { Cunha, K. } \\
\text { S. da; } \\
\text { Higashi, G. } \\
\text { D. C.; } \\
\text { Erdmann, } \\
\text { A. L.; } \\
\text { Kahl, C.; } \\
\text { Koerich, } \\
\text { C.; } \\
\text { Meirelles, } \\
\text { B. H. S. }\end{array}$ & $\begin{array}{c}\text { Pesquisa } \\
\text { qualitativa } \\
\text { ancorada na } \\
\text { Teoria } \\
\text { Fundamentada } \\
\text { nos Dados }\end{array}$ & $\begin{array}{l}\text { Compreender os } \\
\text { fatores que } \\
\text { influenciam o } \\
\text { processo de } \\
\text { referência e } \\
\text { contrarreferência } \\
\text { das pessoas } \\
\text { indicadas / } \\
\text { submetidas à } \\
\text { cirurgia de } \\
\text { Revascularização } \\
\text { do Miocárdio no } \\
\text { cenário da Atenção } \\
\text { Básica à Saúde. }\end{array}$ & $\begin{array}{c}\text { Duas categorias } \\
\text { elucidam os fatores } \\
\text { intervenientes } \\
\text { encontrados, } \\
\text { contrastando as } \\
\text { potencialidades e } \\
\text { obstáculos na (criação) } \\
\text { do vínculo entre as } \\
\text { pessoas acometidas por } \\
\text { doenças cardiovasculares } \\
\text { e a atenção primária à } \\
\text { saúde para o processo de } \\
\text { referência, destacando } \\
\text { fragilidades nos serviços } \\
\text { de atenção primária à } \\
\text { saúde prestados, com } \\
\text { falhas na } \\
\text { contrarreferência para } \\
\text { pessoas submetidas à } \\
\text { cirurgia de } \\
\text { revascularização do } \\
\text { miocárdio. }\end{array}$ & $\begin{array}{l}\text { O fortalecimento das } \\
\text { potencialidades } \\
\text { apresentadas neste } \\
\text { estudo é essencial } \\
\text { para o processo de } \\
\text { referência das pessoas } \\
\text { acometidas pela } \\
\text { doença } \\
\text { cardiovascular, bem } \\
\text { como ações } \\
\text { estratégicas voltadas } \\
\text { para a resolução dos } \\
\text { obstáculos } \\
\text { evidenciados que } \\
\text { contribuem para } \\
\text { deficiências no } \\
\text { processo de referência } \\
\text { e contrarreferência, } \\
\text { impedindo o } \\
\text { atendimento integral } \\
\text { na rede de atenção à } \\
\text { saúde. }\end{array}$ \\
\hline 9 & $\begin{array}{l}\text { Revasculari } \\
\quad \text { zação } \\
\text { miocárdica: } \\
\text { referência e } \\
\text { contrarrefer } \\
\text { ência do } \\
\text { paciente } \\
\text { em uma } \\
\text { instituição } \\
\end{array}$ & $\begin{array}{l}\text { Lanzoni, } \\
\text { G. M. de } \\
\text { M., } \\
\text { Koerich, } \\
\text { C., } \\
\text { Meirelles, } \\
\text { B. H. S., } \\
\text { Erdmann, } \\
\text { A. L., }\end{array}$ & $\begin{array}{c}\text { Pesquisa } \\
\text { qualitativa, } \\
\text { ancorada na } \\
\text { Teoria } \\
\text { Fundamentada } \\
\text { nos Dados. }\end{array}$ & $\begin{array}{l}\text { Compreender o } \\
\text { processo de } \\
\text { referência e } \\
\text { contrarreferência } \\
\text { vivenciado pelo } \\
\text { paciente com } \\
\text { coronariopatia } \\
\text { submetido à } \\
\text { cirurgia de }\end{array}$ & $\begin{array}{l}\text { O processo de referência } \\
\text { e contrarreferência } \\
\text { aponta o fenômeno } \\
\text { "Emergindo a alta } \\
\text { complexidade como } \\
\text { referência para a pessoa } \\
\text { submetida à } \\
\text { revascularização } \\
\text { miocárdica diante da }\end{array}$ & $\begin{array}{l}\text { Para que a referência } \\
\text { aconteça há } \\
\text { necessidade de } \\
\text { consolidar o vínculo } \\
\text { do paciente com } \\
\text { coronariopatia com a } \\
\text { atenção primária à } \\
\text { saúde, uma vez que } \\
\text { este encontra }\end{array}$ \\
\hline
\end{tabular}




\begin{tabular}{|c|c|c|c|c|c|c|}
\hline & hospitalar & $\begin{array}{c}\text { Baggio, M. } \\
\text { A., } \\
\text { Higashi, G. } \\
\text { D. C. }\end{array}$ & & $\begin{array}{l}\text { revascularização } \\
\text { do miocárdio. }\end{array}$ & $\begin{array}{l}\text { fragilidade da Atenção } \\
\text { Primária à Saúde no } \\
\text { acompanhamento e } \\
\text { articulação com os } \\
\text { demais níveis de atenção } \\
\text { no Sistema Único de } \\
\text { Saúde", sustentado por } \\
\text { cinco categorias. }\end{array}$ & $\begin{array}{c}\text { dificuldades no } \\
\text { acompanhamento da } \\
\text { sua condição na rede } \\
\text { pública. Na } \\
\text { contrarreferência } \\
\text { evidenciou-se a } \\
\text { desarticulação entre } \\
\text { os serviços de atenção } \\
\text { à saúde, a qual afeta o } \\
\text { cuidado à pessoa } \\
\text { submetida à } \\
\text { revascularização } \\
\text { miocárdica na } \\
\text { manutenção da sua } \\
\text { qualidade de vida. }\end{array}$ \\
\hline 10 & $\begin{array}{c}\text { Significand } \\
\text { o o } \\
\text { processo de } \\
\text { viver a } \\
\text { cirurgia de } \\
\text { revasculari } \\
\text { zação } \\
\text { miocárdica: } \\
\text { mudanças } \\
\text { no estilo de } \\
\text { vida }\end{array}$ & $\begin{array}{l}\text { Callegaro, } \\
\text { G. D.; } \\
\text { Koerich, } \\
\text { C.; } \\
\text { Lanzoni, } \\
\text { G. M. de } \\
\text { M.; } \\
\text { Baggio, M. } \\
\text { A.; } \\
\text { Erdmann, } \\
\text { A. L }\end{array}$ & $\begin{array}{c}\text { Apresentação } \\
\text { de uma } \\
\text { categoria e } \\
\text { sete } \\
\text { subcategorias, } \\
\text { que } \\
\text { representam as } \\
\text { mudanças } \\
\text { significadas a } \\
\text { partir dessa } \\
\text { experiência, } \\
\text { ou seja, as } \\
\text { "consequência } \\
\text { s", } \\
\text { componente } \\
\text { do modelo } \\
\text { paradigmático, } \\
\text { segundo a } \\
\text { Teoria } \\
\text { Fundamentada } \\
\text { nos Dados, } \\
\text { método do } \\
\text { estudo. }\end{array}$ & $\begin{array}{l}\text { Compreender } \\
\text { como os pacientes } \\
\text { significam seu } \\
\text { processo de viver } \\
\text { após a experiência } \\
\text { cirúrgica de } \\
\text { revascularização } \\
\text { miocárdica }\end{array}$ & $\begin{array}{c}\text { As mudanças } \\
\text { significadas relacionam- } \\
\text { se aos aspectos de vida } \\
\text { social e sexual, trabalho, } \\
\text { alimentação, atividade } \\
\text { física e tratamento } \\
\text { medicamentoso. }\end{array}$ & $\begin{array}{c}\text { A experiência } \\
\text { cirúrgica de } \\
\text { revascularização } \\
\text { incita o refletir e o } \\
\text { (re)pensar o estilo de } \\
\text { vida, apresenta } \\
\text { limitações e } \\
\text { dificuldades que } \\
\text { desafiam adaptações } \\
\text { nos hábitos cotidianos } \\
\text { dos pacientes e } \\
\text { familiares para um } \\
\text { processo de viver } \\
\text { mais saudável. }\end{array}$ \\
\hline 11 & $\begin{array}{c}\text { Temporalid } \\
\text { ade da } \\
\text { mulher } \\
\text { após } \\
\text { cirurgia } \\
\text { cardíaca: } \\
\text { contribuiçõo } \\
\text { es para o } \\
\text { cuidado de } \\
\text { enfermage } \\
\text { m }\end{array}$ & $\begin{array}{c}\text { Amorim } \\
\text { T.V.; } \\
\text { Salimena } \\
\text { A.M.O; } \\
\text { Souza } \\
\text { Í.E.O, } \\
\text { Melo } \\
\text { M.C.S.C.; } \\
\text { Silva L. F.; } \\
\text { Cadete, } \\
\text { M.M.M }\end{array}$ & $\begin{array}{c}\text { Pesquisa } \\
\text { qualitativa de } \\
\text { abordagem } \\
\text { fenomenológic } \\
\text { a com } \\
\text { analítica } \\
\text { sustentada no } \\
\text { referencial de } \\
\text { Martin } \\
\text { Heidegger }\end{array}$ & $\begin{array}{c}\text { Desvelar o } \\
\text { movimento } \\
\text { existencial da } \\
\text { mulher após a } \\
\text { intervenção } \\
\text { cirúrgica cardíaca. }\end{array}$ & $\begin{array}{l}\text { Após a alta hospitalar, as } \\
\text { mulheres vivenciam } \\
\text { comprometimentos } \\
\text { físicos, sociais e } \\
\text { emocionais, desejando a } \\
\text { volta do tempo anterior } \\
\text { ao diagnóstico, uma vez } \\
\text { que ainda se sentem } \\
\text { cardiopatas. Essa } \\
\text { compreensão vaga e } \\
\text { mediana emerge de três } \\
\text { unidades de significação, } \\
\text { as quais, na perspectiva } \\
\text { da hermenêutica } \\
\text { heideggeriana, } \\
\text { permitiram desvelar o } \\
\text { fenômeno da cirurgia } \\
\text { cardíaca como um agora } \\
\text { que limita o dia a dia das } \\
\text { mulheres. }\end{array}$ & $\begin{array}{l}\text { O enfermeiro, na } \\
\text { disposição de ser- } \\
\text { com-o-ser-aí-mulher- } \\
\text { após-a-cirurgia- } \\
\text { cardíaca, deve } \\
\text { promover a saúde, } \\
\text { considerando as } \\
\text { facetas existenciais } \\
\text { que se mostram nos } \\
\text { momentos de } \\
\text { cuidado. Nessa } \\
\text { oportunidade de } \\
\text { encontros singulares e } \\
\text { plenos de } \\
\text { subjetividade se } \\
\text { revelam as bases para } \\
\text { a integralidade da } \\
\text { assistência. }\end{array}$ \\
\hline
\end{tabular}


O Estado de Santa Catarina foi o que obteve maior número de evidências científicas disponíveis referentes ao tema da pesquisa, com um total de sete (64\%) estudos. Também encontramos publicações no Paraná com dois (18\%) estudos, e no Ceará e Minas Gerais, cada estado com um (9\%) estudo disponível.

Em relação ao ano de publicação, verificou-se atualidade do maior número publicações encontradas, fator este que pode contribuir para a continuidade da pesquisa referente ao assunto. Em 2018 foram publicados cinco (46\%) estudos referentes ao tema, seguido por dois (18\%) estudos no ano de 2016, e um (9\%) estudo nos anos de 2010, 2012, 2015, e 2017. Não foram selecionados artigos dos anos de 2011, 2013, 2014, 2019 e 2020, por não atenderem aos critérios de elegibilidade.

Referente aos periódicos, a Revista Brasileira de Enfermagem obteve destaque, com cinco (46\%) estudos disponíveis. Outros periódicos onde encontramos artigos foram em Repositório Digital Institucional da UFPR, Revista Brasileira em Promoção da Saúde (RBPS), Revista Comunicação em Ciências da Saúde, Revista da Escola de Enfermagem da USP, Revista Gaúcha de Enfermagem, e Texto \& Contexto Enfermagem, cada periódico com um estudo (9\%) cada.

Os artigos analisaram diferentes grupos de participantes, obtivemos estudos que analisaram um grupo de participantes especificamente, bem como estudos que estudaram até três grupos de participantes. Para melhor entendimento dos dados, realizamos uma divisão dos grupos de participantes estudados nas pesquisas, com a seguinte classificação:

Grupo 1: pacientes submetidos à intervenção cirúrgica cardíaca; profissionais de saúde e gestores de saúde.

Grupo 2: pacientes submetidos à intervenção cirúrgica cardíaca; profissionais de saúde e familiares dos pacientes.

Grupo 3: pacientes submetidos à intervenção cirúrgica cardíaca.

Grupo 4: enfermeiras dos diferentes níveis de atenção à saúde (APS, Serviço Hospitalar, Unidade de Pronto Atendimento (UPA)).

Grupo 5: enfermeiras dos diferentes níveis de atenção à saúde (APS, Hospital, UPA) e usuários dos serviços de saúde.

O Grupo 1 foi analisado em seis (55\%) estudos, o Grupo 3 em dois (18\%) estudos e o grupo 2, 4 e 5 em apenas um (9\%) estudo cada. De outra forma explicativa, dos onze estudos encontrados nove deles analisaram os pacientes submetidos à intervenção cirúrgica; nove avaliaram os profissionais de saúde dos diferentes níveis de atenção à saúde (APS, Hospital, UPA), entre estes profissionais encontramos enfermeiros, assistentes sociais, médicos, educadores físicos, agentes comunitários de saúde e técnicos de enfermagem, com ênfase no profissional enfermeiro. Seis estudos incluíram como participantes os gestores dos serviços de saúde. Um estudo inseriu em sua pesquisa os familiares dos pacientes submetidos à intervenção cirúrgica, e outro estudo incluiu em sua pesquisa os usuários dos serviços de saúde, estando inclusos nesse grupo amostral os pacientes submetidos à intervenção cirúrgica.

Por fim, 10 (91\%) estudos utilizaram uma abordagem qualitativa em sua pesquisa, e apenas um (9\%) estudo utilizou uma abordagem quanti-qualitativa. Na Tabela 1 é possível observarmos as variáveis referente as especificações dos artigos científicos utilizados nesta revisão. Esses dados foram distribuídos em uma tabela de porcentagem, possibilitando um comparativo entre os estudos selecionados, analisando os seguintes itens: local da realização da pesquisa, ano de publicação, periódico de publicação, participantes do estudo, e abordagem de cada artigo. 
Tabela 1. Tabela de porcentagem, referente as especificações dos artigos científicos utilizados nesta revisão.

\begin{tabular}{|c|c|}
\hline Variáveis & Porcentagem (\%) \\
\hline \multicolumn{2}{|l|}{ Local de realização da pesquisa } \\
\hline Ceará & $9 \%$ \\
\hline Minas Gerais. & $9 \%$ \\
\hline Paraná & $18 \%$ \\
\hline Santa Catarina & $64 \%$ \\
\hline \multicolumn{2}{|l|}{ Ano de publicação } \\
\hline 2010 & $9 \%$ \\
\hline 2012 & $9 \%$ \\
\hline 2015 & $9 \%$ \\
\hline 2016 & $18 \%$ \\
\hline 2017 & $9 \%$ \\
\hline 2018 & $46 \%$ \\
\hline \multicolumn{2}{|l|}{ Periódico de publicação } \\
\hline Repositório Digital Institucional da UFPR & $9 \%$ \\
\hline Rev. Bras. Enferm & $46 \%$ \\
\hline Rev. Bras. em Promoção da saúde (RBPS) & $9 \%$ \\
\hline Rev. Com. Ciências Saúde & $9 \%$ \\
\hline Rev. Esc. Enferm. USP & $9 \%$ \\
\hline Rev Gaúcha Enferm & $9 \%$ \\
\hline Texto Contexto Enferm. & $9 \%$ \\
\hline \multicolumn{2}{|l|}{ Participantes do estudo } \\
\hline Grupo 1 & $55 \%$ \\
\hline Grupo 2 & $9 \%$ \\
\hline Grupo 3 & $18 \%$ \\
\hline Grupo 4 & $9 \%$ \\
\hline Grupo 5 & $9 \%$ \\
\hline \multicolumn{2}{|l|}{ Abordagem utilizada } \\
\hline Qualitativa & $91 \%$ \\
\hline Quanti-qualitativa & $9 \%$ \\
\hline
\end{tabular}

Fonte: Dados da pesquisa (2020).

Referente aos dados encontrados, verificou-se a importância de subdividir esta Revisão Integrativa em quatro tópicos, para melhor discussão das evidências científicas encontradas referente ao tema. Primeiramente, compreendeu-se a necessidade de identificar o perfil dos pacientes que se submetem ao procedimento cirúrgico cardíaco. Posteriormente, buscou-se analisar os seguintes itens: o processo de referência e contrarreferência das redes de atenção à saúde; a educação em saúde e a continuidade da assistência nos diferentes serviços de saúde, e por último, a readmissão hospitalar e a qualidade de vida dos pacientes submetidos à cirurgia cardíaca. 


\subsection{Caracterização dos Pacientes Submetidos à Cirurgia Cardíaca}

As doenças cardiovasculares (DCV) encontram-se na lista das principais causas de morbimortalidade mundial. São caracterizadas por sua causa multifatorial, englobando aspectos hereditários, fatores comportamentais de risco e história clínica do paciente. A resolutividade do prognóstico de pacientes acometidos por DCV pode ser clínica ou cirúrgica, dependendo da situação da doença, sintomas de gravidade e outras condições do paciente. (Koerich et al., 2017; Organização Pan-Americana da Saúde, 2020).

Referente ao tratamento cirúrgico, temos como técnica primordial para o tratamento das doenças isquêmicas do coração, a cirurgia de revascularização do miocárdio (CRM), considerada um método eficaz no tratamento dessas doenças e que tem por objetivo a correção da isquemia miocárdica, que ocasiona a obstrução das artérias coronárias. É a principal escolha entre os profissionais de saúde, pois essa opção cirúrgica possibilita melhor qualidade de vida, bem como o aumento da sobrevida desses pacientes. Com isso, verificamos a importância de identificar o perfil epidemiológico dos pacientes que necessitam de intervenção cirúrgica para o tratamento das DCV. (Kaufman et al., 2011; Oliveira et al., 2012).

Segundo informações de estudos podemos verificar que a caracterização da população submetida a CRM é de pessoas do gênero masculino, autodeclaradas brancas, casadas e aposentadas, com maior taxa de prevalência em adultos entre 50 e 70 anos. Outro fator interessante a ressaltar é o baixo nível de escolaridade em grande parte da população analisada, fator este que pode interferir em questões como a educação em saúde referente sua condição clínica e adesão a hábitos de vida saudáveis, aspectos que poderiam intervir no aparecimento de comorbidades associadas as DCV. (Koerich et al., 2017; Oliveira et al., 2012).

Em relação as comorbidades associadas, encontramos em destaque a Hipertensão Arterial Sistêmica (HAS) e Diabetes Mellitus (DM), além de Insuficiência Renal, Doença Cerebrovascular, Doença Pulmonar Obstrutiva e Cardiopatias. E referente aos fatores de risco, foram identificados: pressão arterial sistêmica elevada, histórico familiar, dislipidemia, tabagismo, glicemia elevada, e história clínica de infarto agudo do miocárdio (IAM) prévio. (Koerich et al., 2017; Oliveira et al., 2012).

\subsection{Referência e Contrarreferência das Unidades de Saúde}

A APS é vista como a principal porta de entrada do SUS, ou seja, o primeiro nível de atenção à saúde. Por meio dela, é possível realizar a comunicação com a Rede de Atenção à Saúde (RAS) do SUS, funcionando como um mecanismo para organização do fluxo dos serviços de saúde, encaminhando os pacientes para os diferentes níveis de assistência dos serviços de saúde (média e alta complexidade). Os pacientes com DCV quando se encontram em uma emergência cardíaca, encaminhamse para os diferentes níveis da assistência à saúde (APS, UPA e Emergência Hospitalar), sendo que a resolutividade da situação se difere nesses ambientes de assistência, dependendo da conduta adotada pela equipe de saúde. (Erdmann et al., 2017; Lanzoni et al., 2018; Ministério da Saúde, 2020).

Os profissionais da APS, após avaliação da condição clínica, realizam o encaminhamento desses pacientes para a UPA ou para a emergência hospitalar. Na UPA, os profissionais de saúde buscam estabilizar o quadro clínico do paciente para posterior encaminhamento ao serviço hospitalar, por meio do paciente/família ou pelo serviço móvel de urgência. Essas condutas caracterizam o processo de referência ao serviço de saúde de alta complexidade. (Erdmann et al., 2017; Lanzoni et al., 2018).

Em mais da metade dos casos a primeira escolha dos pacientes é a emergência hospitalar, essa decisão se deve ao fato dos pacientes se sentirem mais seguros ao se deslocar para este ambiente assistencial, devido ao acesso a exames e avaliação imediata com especialistas. Em algumas situações, os pacientes optam em direcionar-se aos serviços de saúde particulares, com o objetivo de obter consultas com profissionais clínicos, especialistas e realização de exames. Essa escolha se justifica pela demora da aquisição dessa assistência no serviço público. (Erdmann et al., 2017; Lanzoni et al., 2018). 
Referente ao processo de contrarreferência dos pacientes submetidos a cirurgia cardíaca, encontramos uma barreira por parte dos profissionais do serviço hospitalar. Estes profissionais evitam a realização de contrarreferência aos serviços de baixa complexidade, pois acreditam que esses serviços de saúde não possuem capacitação, recursos físicos e recursos humanos para realizar uma assistência de qualidade a esse grupo peculiar de pacientes. A crítica dos profissionais baseia-se na ausência de especialistas e profissionais capacitados para a resolutividade dos casos complexos, que necessitam de suporte especializado para garantia de uma assistência de qualidade. Esse é um fator que implica diretamente na articulação e comunicação dos serviços de saúde. (Erdmann et al., 2017; Lanzoni et al., 2018).

É importante evidenciar que para fornecer atenção integral e continuada ao paciente é necessário a integração dos serviços de saúde, que é possível por meio dos processos de referência e contrarreferência. Possibilitando uma assistência qualificada ao paciente, fornecendo promoção a saúde, tratamento de doenças e agravos à saúde, reabilitação da condição clínica e acompanhamento continuado ao paciente. Torna-se interessante o desenvolvimento de instrumentos que facilitam o processo de referência e contrarreferência. Sendo o desenvolvimento, aplicação e monitoramento de protocolos feito por profissionais e gestores de saúde, visando a integração dos serviços. (Erdmann et al., 2017; Lanzoni et al., 2018).

A comunicação entre a APS e o serviços de média e alta complexidade afetam diretamente na continuidade da assistência ao paciente. A contrarreferência fragilizada fornece ao profissional enfermeiro dificuldade para acompanhar o quadro clínico do paciente, pois encontra-se sem informações suficientes para fornecer o devido atendimento, sendo que poucos pacientes recebem orientações para o retorno à APS. Também há ausência da interligação entre os serviços de saúde e falta de unificação das informações que constam nos prontuários eletrônicos, levando a dificuldade na continuidade da assistência ao paciente encaminhado. (Miotello et al., 2020).

O profissional enfermeiro possui a capacidade de inovação do processo de referência e contrarreferência, ao aplicar a função de "enfermeiro(a) de ligação". Esta atividade possibilita interação entre os profissionais enfermeiros dos distintos serviços de saúde, buscando avaliar e compreender as necessidades individuais dos pacientes após a alta hospitalar, e realizar o planejamento e organização dos recursos disponíveis na APS para o fornecimento da assistência adequada ao paciente. Esta interação também possibilita a compreensão dos profissionais referente ao funcionamento dos serviços nas RAS. (Ribas et al., 2018).

Nesse contexto, a enfermeira possibilita a ligação entre o hospital e a APS. Essa atividade possui grande importância para a continuidade da assistência ao paciente na APS. A enfermeira de ligação contribui no planejamento de alta do paciente hospitalizado, organizando a melhor conduta para a continuidade da assistência. Um fator que pode intervir nessa função é a falta de tempo do profissional enfermeiro e ausência de recursos humanos suficientes para desempenhar esta função. Por isso, existe a necessidade da exclusividade de um profissional enfermeiro para desempenhar esta função em específico, já que é um método que contribui positivamente para a continuidade da assistência na APS. (Ribas et al., 2018).

\subsection{Educação em Saúde e a Continuidade da Assistência}

Segundo pacientes com DCV ou submetidos a CRM, muitas são as dificuldades encontradas na APS, como o número de consultas médicas reduzido, excesso de trabalho dos profissionais de saúde, atendimento em horários incompatíveis com o horário comercial, pouca solução dos problemas clínicos dos pacientes na APS e ausência de especialização profissional, fator este que afeta o diagnóstico precoce de pacientes com DCV. (Kahl et al., 2018; Lanzoni et al., 2018).

Observamos que a maior parte dos pacientes submetidos a cirurgia cardíaca possuem baixo nível de escolaridade, esse dado fica evidente quando constatamos que a condição clínica de muitos pacientes é agravada devido à falta de conhecimento referente a sintomatologia da doença. Por não compreenderem a gravidade dos sinais e sintomas acabam ignorando o prognóstico da patologia e a busca pela devida assistência, essa condição leva ao agravamento da doença, comprometimento 
das atividades cotidianas e dificuldade na resolutividade da situação. (Kahl et al., 2018; Lanzoni et al., 2018).

Com isso, verificamos a importância da educação em saúde nos diferentes níveis da assistência. Durante a internação do paciente, é o momento para o desenvolvimento de um plano de cuidados específico para a continuidade da assistência na APS, realizando orientações que forneçam um adequado acompanhamento da doença, recuperação do paciente, adesão ao tratamento e melhora na qualidade de vida. (Kahl et al., 2018; Lanzoni et al., 2018).

O Enfermeiro é visto como um elo entre o serviço hospitalar e a APS. Através da implementação de um plano de cuidados por meio da educação em saúde ainda na fase de hospitalização, é possível auxiliar na continuidade do tratamento após a alta hospitalar, proporcionar a diminuição dos índices de reinternação hospitalar, possibilitar a inserção do paciente e família na recuperação e tratamento do usuário, e favorecer a resolução nos processos de encaminhamentos. (Lanzoni et al., 2018).

O método de educação em saúde fornece diversos benéficos para o paciente e equipe de saúde que acompanha seu prognóstico. Essa tarefa é atribuída ao profissional enfermeiro durante as consultas de enfermagem, onde a avaliação clínica pode ser realizada, visando a busca de diagnósticos e risco de futuros diagnósticos de enfermagem. Neste processo, torna-se possível a formulação e/ou atualização do plano de cuidados adequado para a condição clínica atual do paciente, a fim de possibilitar a promoção de saúde e a recuperação do usuário dos serviços da RAS. (Oliveira et al., 2020).

Para o profissional enfermeiro, podemos destacar alguns benefícios ao empregar a educação em saúde no processo cuidativo aos pacientes nos diferentes níveis da assistência à saúde. Identificamos como benefícios o desenvolvimento de uma linguagem científica, formulação do pensamento crítico e aplicação do raciocínio clínico, fatores esses que propiciam ao fornecimento da assistência de maior qualidade ao paciente assistido. (Oliveira et al., 2020).

O enfermeiro da APS é responsável por diversas tarefas dentro da unidade, como a organização do serviço, supervisão e cuidados desenvolvidos pela equipe de saúde (Agentes Comunitários de Saúde - ACS e Equipe de Enfermagem), a fim de possibilitar um adequado funcionamento do serviço de saúde à população. O reconhecimento do enfermeiro na APS vem tornando-se cada vez mais presente, pois os usuários do serviço identificam o profissional como referência para seu cuidado, fornecendo ao enfermeiro satisfação e sentido ao seu trabalho. (Ferreira et al., 2018).

Para o profissional enfermeiro outras atividades que o competem, são: o exercício do raciocínio e prática clínica através das consultas de enfermagem, criação de vínculo com a comunidade atendida, e estabelecimento de um bom relacionamento interpessoal com a equipe de saúde (médicos, equipe de enfermagem e ACS), para que o desenvolvimento da assistência à saúde ocorra em um ambiente de trabalho adequado e saudável. (Ferreira et al., 2018).

A atuação do enfermeiro torna-se fundamental para a continuidade da assistência ao paciente na APS, pois este profissional é considerado um facilitador do acesso ao vínculo entre os pacientes e os demais profissionais da equipe de saúde. Por meio das consultas médicas e de enfermagem é realizado o acompanhamento dos pacientes, sendo as consultas de enfermagem direcionadas preferencialmente ao fornecimento de orientações e cuidados de enfermagem, respeitando a especificidade de cada indivíduo. (Miotello et al., 2020).

No primeiro momento o profissional enfermeiro realiza o acolhimento do paciente, coletando dados e informações para o preenchimento do histórico, condição de saúde atual, queixas, sinais e sintomas clínicos relatados pelo paciente e família, bem como avaliação não verbal do paciente. Por meio do enfermeiro, essas informações são repassadas ao médico generalista da unidade, que avalia a condição clínica do paciente para possível solicitação de exames e encaminhamentos para outros níveis dos serviços de saúde, quando há necessidade. (Miotello et al., 2020).

No serviço de ESF, são realizadas discussões dos casos dos pacientes durante as reuniões mensais da unidade. Por meio desta atividade, as informações são compartilhadas entre a equipe de saúde para o desenvolvimento de um plano de cuidados ideal para cada paciente. Através do trabalho desenvolvido por ACS nas visitas domiciliares, é possível identificar 
pacientes que se encontram em situação de risco, como os pacientes submetidos à cirurgia cardíaca, após identificá-los os ACS comunicam ao enfermeiro da unidade, que gerencia as informações do paciente e a equipe de saúde, tendo a responsabilidade de definir a conduta que será adotada ao paciente em situação de risco. (Miotello et al., 2020).

As consultas de enfermagem possibilitam diversos benefícios na continuidade da assistência ao paciente atendido. Por meio desta ação, é fornecido o esclarecimento de dúvidas do paciente relacionadas ao seu quadro clínico e tratamento, bem como orientações para melhora de sua qualidade de vida. Também é possível identificar aspectos clínicos, emocionais e psicológicos que o paciente venha a apresentar, possibilitando o encaminhamento a outros profissionais específicos para suas necessidades, como fisioterapeutas, psicólogos, assistentes sociais, entre outros. (Miotello et al., 2020).

Em alguns casos os profissionais avaliam os pacientes e identificam a necessidade do encaminhamento aos serviços de saúde de maior complexidade, visando o atendimento com especialistas. Porém, após o encaminhamento a continuidade da assistência destes pacientes na APS diminui, dado este que pode embasar-se no fato dos pacientes acreditarem que já estão com atendimento clínico específico e não necessitam mais da assistência na APS por médicos generalistas. Por meio da falha no processo de contrarreferência, o profissional enfermeiro não possui informações referente a evolução do quadro do paciente, por conseguinte, não é possível avaliar as necessidades que o paciente apresenta e realizar a devida continuidade da assistência de enfermagem. (Miotello et al., 2020).

A ausência de conhecimento específico para o atendimento a pacientes com alterações cardiovasculares é um fator que afeta a resolutividade dos casos. Este grupo de pacientes possuem alterações complexas e que necessitam de conhecimento específico e estudo contínuo. O fornecimento da capacitação aos profissionais de saúde é um fator de extrema relevância, por meio desta ação é possível a aquisição de melhora no atendimento e acompanhamento destes pacientes. (Miotello et al., 2020).

\subsection{Readmissão Hospitalar e Qualidade de Vida de Pacientes Submetidos à Cirurgia Cardíaca}

É necessária adaptação na rotina e mudanças nos hábitos de vida após o procedimento cirúrgico vivenciado por estes pacientes, a fim de proporcionar adequada recuperação cardíaca e qualidade de vida. Em muitos casos, os pacientes são readmitidos no ambiente hospitalar devido a alguma necessidade/emergência clínica. Essas readmissões hospitalares podem ser separadas em dois tipos: as planejadas, quando há necessidade de sua ocorrência para devida continuidade da assistência e avaliação diagnóstica ou terapêutica do paciente; e as eventuais, que podem ser definidas como evitáveis e não evitáveis, sendo sua classificação relacionada ao intervalo de tempo entre a primeira admissão e a reinternação. (Kossovsky et al., 1999; Kirby et al., 2010).

Grande parte das readmissões potencialmente evitáveis ocorrem devido a complicações pós-operatórias e de DCV. A concreticidade destes dados pode estar relacionada com a necessidade do envolvimento do paciente no tratamento de sua doença, e reestabelecimento de sua condição clínica. Outros fatores que podem influenciar estes resultados são: deficiência do conhecimento específico de cada condição clínica por meio dos profissionais de saúde nos diferentes níveis de assistência, insuficiente gerenciamento da condição clínica do paciente, inadequado planejamento do plano de cuidados após a alta, e inexistente acessibilidade de recursos para assistência ao paciente em âmbito domiciliar. (Borges \& Turrini, 2011; Kirby et al., 2010).

Torna-se evidente a ausência da continuidade dos pacientes nas consultas, processo esse que visa a prevenção e/ou detecção precoce das DCV, bem como, diminuição de reinternações hospitalares e melhora na qualidade de vida dos pacientes. Porém, é de extrema importância a adesão do indivíduo atendido ao seu tratamento, alterando os hábitos comportamentais e biopsicossociais que possam afetar a reabilitação do seu quadro clínico. (Borges \& Turrini, 2011; Kirby et al., 2010; Kahl et al., 2018; Lanzoni et al., 2018).

A APS possui um papel de grande importância relacionado as readmissões hospitalares, pois os números de 
hospitalizações reduzem perante o tratamento de condições sensíveis, incluindo as DCNT, fora do ambiente hospitalar. Condições sensíveis são aquelas em que a internação hospitalar se torna potencialmente evitável devido a prevenção, gerenciamento da doença e acompanhamento do paciente, ações fornecidas pelos profissionais na APS. (Kirby et al., 2010).

É por meio das consultas de enfermagem que o enfermeiro possui a habilidade do desenvolvimento de um plano de cuidados para o paciente, buscando ações que possibilitem melhora no seu bem-estar geral e na qualidade de vida, abordando aspectos relacionados a seus hábitos comportamentais, como alimentação adequada e regularidade das atividades físicas. (Miotello et al., 2020).

Após a alta hospitalar muitos pacientes retomam hábitos de vida anteriores a cirurgia cardíaca, sendo possível que esses fatores comportamentais direcionem o paciente a sua condição clínica atual, levando o paciente então, a uma possível readmissão hospitalar. A conscientização do paciente é um fator de extrema influência, já que este individuo precisa compreender que mudanças devem ocorrer para proporcionar melhora da sua qualidade de vida. O ideal é que haja controle dos fatores de risco que prejudicam o quadro de saúde do paciente. Este fator varia de caso para caso, mas no geral ocorrem mudanças referente a atividade física, alimentação, controle de peso, tabagismo, esforço físico e estresse. (Oliveira et. al., 2010).

A adesão e comprometimento do paciente com as mudanças em seus hábitos diários, são fatores determinantes para sua reabilitação clínica. É comprovado que a atividade física regular proporciona benefícios ao paciente com DCV ou póscirúrgico, pois possibilita a prevenção primária e secundária, além de auxiliar no tratamento de DCV. A regularidade de atividade física associada a orientações referente as mudanças nos hábitos de vida, proporciona ao paciente diminuição das complicações pós-operatórias, dos níveis de mortalidade e das readmissões hospitalares. (Nery et al., 2007).

Os hábitos alimentares também exigem mudanças, pois uma má alimentação compromete a qualidade de vida do paciente. Maus hábitos alimentares associados com a inatividade física levam o indivíduo ao desenvolvimento de sobrepeso e obesidade, fatores que prejudicam o paciente nas diversas fases do processo operatório. Com isso, ocorre influência direta na tolerância ao procedimento cirúrgico, período de internação e reabilitação, risco de infecção e cicatrização das feridas operatórias, estado clínico do indivíduo e tratamento de seu processo de saúde-doença. (Araujo et al., 2014).

Outro fator de risco que necessita de atenção é o tabagismo, considerada uma prática que está associada ao surgimento de graves DCV e respiratórias e que tende a cessar após a cirurgia cardíaca. A cessação do fumo após o procedimento cirúrgico pode ser justificada pela situação de internação hospitalar em que o paciente se expõe. É possível que o enfermeiro e a equipe multidisciplinar orientem o paciente e a família sobre a cessação do fumo durante a internação hospitalar e posteriormente, nas consultas de enfermagem e médicas realizadas na APS, onde poderão ser apresentados os riscos que este hábito acarreta, bem como os benefícios que acompanham sua cessação. (Organização Pan-Americana da Saúde, 2019; Pietrobon \& Barbisan, 2010).

Destaca-se também o vínculo desenvolvido pelo enfermeiro e paciente durante a assistência, pois com ele há fornecimento de uma melhor identificação do profissional frente a condições que possam prejudicar a saúde do paciente. Possibilita também a adesão do ínvido ao tratamento e orientações para melhorar sua qualidade de vida, buscando a promoção, recuperação e manutenção da saúde do paciente. (Bin et al., 2014; Lanzoni et al., 2015).

Muitos pacientes podem apresentar dificuldade e insatisfação com os novos hábitos de vida diários. Verificamos que o paciente é o único que consegue constatar a satisfação da sua qualidade de vida, realizando autopercepção referente ao seu quadro de saúde e condição de vida atual. Essas mudanças comportamentais podem apresentar-se de forma dificultosa para o paciente, o facilitador ocorre quando os pacientes compreendem a necessidade de mudanças no estilo de vida para uma sobrevida de maior qualidade. A qualidade de vida para os pacientes que passaram pela cirurgia cardíaca engloba a felicidade, a satisfação com sua condição atual e o bem-estar no seu novo estilo de vida e no processo de saúde-doença. (Oliveira et al., 
2010).

O paciente submetido à cirurgia cardíaca encontra-se com o emocional, físico e psicológico abalados devido as condições submetidas, necessitando de uma rede de apoio sólida para o enfrentamento do seu processo de saúde-doença. Com isso, o suporte familiar e de amigos é essencial durante a adaptação a um novo estilo de vida, sendo que os pacientes também relatam a importância da crença religiosa durante todas as fases do processo de saúde-doença. (Bin et al., 2014; Lanzoni et al., 2015).

Podemos compreender que existe certa dificuldade na adaptação de novos hábitos de vida após o procedimento cirúrgico, já que os pacientes necessitam se adequar a uma realidade distinta da vivida anteriormente. Por isso, a rede de apoio torna-se de extrema importância, pois além das mudanças nos fatores comportamentais diários, muitos pacientes necessitam se adaptar a uma vida sem o trabalho, devido a impossibilidade ou incapacidade para desempenhar as atividades de serviço. $\mathrm{O}$ apoio familiar associado as orientações fornecidas pelos profissionais de saúde, possibilitam a amenização do sofrimento vivenciado pelo paciente e o encorajamento a buscar novas atividades que se adequem ao seu novo processo de viver. (Callegaro et al., 2012).

\section{Conclusão}

A APS é o ambiente que possibilita o acompanhamento próximo da evolução dos pacientes atendidos. Por meio deste serviço, é possível realizar prevenção, diagnósticos, tratamentos, monitoramento e promoção da saúde da comunidade. Quando o trabalho na APS é desenvolvido adequadamente, é possível identificar os sinais e sintomas de doenças e agravos à saúde, e por meio da prevenção, evitar o encaminhamento dos pacientes aos serviços de média e alta complexidade.

Os artigos encontrados evidenciaram a grande dificuldade no processo de referência e contrarreferência das RAS. Os profissionais da saúde no âmbito hospitalar, diminuem a eficiência da assistência que pode ser fornecida a esse grupo de pacientes nos serviços de baixa complexidade. Porém, compreende-se pouca especialização dos profissionais da APS referente a alterações de saúde mais complexas, como as DCV. Esse fator se justifica devido a sobrecarga de trabalho que é exigida dos profissionais desse serviço. Atender a alta demanda de pacientes de uma comunidade, compreendendo aspectos de diferentes doenças e agravos à saúde é uma tarefa de grande exigência.

A contrarreferência fragilizada prejudica a continuidade da assistência na APS, porém é necessário que os profissionais de saúde compreendam o objetivo de proporcionar um bom prognóstico ao paciente. Levando isso em consideração, a enfermeira de ligação é uma atividade que traz resultados positivos para continuidade do cuidado. É necessário o aumento desta atividade para favorecer o processo de referência e contrarreferência, e assim torná-lo mais recorrente, para benefício da saúde dos indivíduos. O reconhecimento do trabalho desenvolvido por enfermeiros na APS é de grande importância, pois estes enfrentam diversas dificuldades em sua rotina de trabalho, lidando com as complexidades da comunidade, sobrecarga do serviço, recursos materiais e humanos limitados, e com o gerenciamento da unidade e equipe de saúde. O profissional enfermeiro é responsável por muitas atividades dentro da APS, este aspecto pode influenciar a pouca especialização desses profissionais em áreas da saúde que necessitam de um maior conhecimento, como as DCV e cirurgias cardiovasculares. Este fator não pode ser considerado de responsabilidade do enfermeiro, já que este necessita gerenciar seu tempo e recursos para possibilitar o melhor funcionamento da unidade de saúde.

Dentre as diversas atividades desenvolvidas pelo enfermeiro, as consultas de enfermagem são as que possibilitam maior resolutividade dos casos. Esta prática evidencia diversos pontos positivos para a continuidade da assistência na APS. Por meio dela, o profissional enfermeiro consegue desenvolver suas habilidades em prol do bem-estar do paciente atendido. Uma das possibilidades fornecidas pelas consultas de enfermagem é o vínculo entre paciente e enfermeiro, que possibilita maior adesão do paciente ao seu tratamento e orientações fornecidas pelo profissional, além de possibilitar a coleta de dados pelo 
enfermeiro e seu repasse ao restante da equipe para que após análise e discussões do caso, possa ser realizada a melhor conduta ao paciente.

Durante as consultas de enfermagem também é possível aplicar a educação em saúde ao paciente e família, orientando-os referente ao processo de saúde-doença, sanando dúvidas e questionamentos, e fornecendo a escuta terapêutica que é uma prática que aumenta a confiança entre o paciente e o enfermeiro, sendo possível também avaliar sinais e sintomas que possam indicar complicações ou diagnósticos futuros. Possuindo como objetivo final a melhora na qualidade de vida do paciente assistido, por meio de técnicas e orientações que visem a promoção da saúde do indivíduo e a adaptação ao seu novo estilo de vida.

Durante a internação hospitalar ocorre o desenvolvimento do plano de cuidados, que posteriormente é adaptado na APS conforme a evolução clínica do paciente. O plano de cuidados é a forma de avaliar a condição do indivíduo, e em cima dessa análise, possibilitar a conduta adequada a ser seguida pele equipe de saúde. Porém o fator que prejudica drasticamente a continuidade da assistência, é a falta de interesse dos pacientes em comparecerem as consultas e seguir o tratamento recomendado.

Para alguns pacientes, as mudanças ocorridas em seus hábitos diários podem ser drásticas, porém compreendemos que são práticas necessárias para a evolução de seu quadro de saúde, evitando futuras complicações e readmissões hospitalares. As alterações que devem ser realizadas envolvem os hábitos alimentares, atividade física, sentimento em relação a qualidade de vida, estresse, apoio familiar, ausência de atividade trabalhista e adaptação a novas práticas de lazer. Porém, por mais que possam apresentar resistência em se submeter a uma nova rotina, é necessário que o enfermeiro insista nestes aspectos, fornecendo as devidas orientações ao paciente e sua família, tornando este momento menos dificultoso e proporcionando a promoção da saúde do paciente.

Verificou-se que os pacientes acometidos por DCV e submetidos à cirurgia cardíaca estão sujeitos a enfrentar diversas alterações em sua vida, envolvendo aspectos físicos, emocionais e psicossociais, bem como seus cuidadores familiares que se encontram sobrecarregados pela demanda de atividades. Percebeu-se também, que por meio de técnicas assistenciais relevantes, como a escuta terapêutica, e pelo olhar diferenciado do enfermeiro, compreendendo o paciente como um ser amplo e complexo, a assistência de enfermagem na APS apresenta-se de forma diferenciada, resultando em uma aplicação positiva para o processo cuidativo dos pacientes.

Por fim, sugere-se para os futuros trabalhos desenvolvidos, a constante busca de conhecimento técnico e científico a respeito da temática, evidenciando a importância da compreensão referente ao processo cuidativo do enfermeiro no acompanhamento dos pacientes de pós-cirurgia cardíaca na APS. É necessário que haja fundamentação teórica atualizada para o desenvolvimento de futuras pesquisas, pois compreendemos as especificidades deste grupo de pacientes e as necessidades que devem ser supridas por meio da continuidade da assistência desempenhada pelos profissionais de saúde. Como referido anteriormente, o enfermeiro na APS possui um papel de extrema importância na continuidade do cuidado, por meio de técnicas assistenciais de qualidade, desenvolvimento de plano de cuidados específicos e realizações de consultas de enfermagem, com o objetivo de prevenir, promover e/ou recuperar a saúde dos pacientes assistidos.

\section{Referências}

Araújo, N. R. de, Araújo, R. A. de, \& Bezerra, S. M. M. da S. (2014). Sobrepeso e repercussão da obesidade no pós-operatório de cirurgia de revascularização miocárdica. Revista da Escola de Enfermagem da USP, 48(2), 236-241. https://dx.doi.org/10.1590/S0080-623420140000200006

Balduino, A. de F. A., Mantovani, M. de F., \& Lacerda, M. R. (2009). O processo de cuidar de enfermagem ao portador de doença crônica cardíaca. Escola Anna Nery, 13(2), 342-351. https://doi.org/10.1590/S1414-81452009000200015

Bin, G., Costa, M. C. S., Vila, V. da S. C., Dantas, R. A. S., \& Rossi, L. A. (2014). Significados de apoio social de acordo com pessoas submetidas à revascularização do miocárdio: estudo etnográfico. Revista Brasileira de Enfermagem, 67 (1), 71-77. https://dx.doi.org/10.5935/0034-7167.20140009 
Borges, M. F., \& Turrini, R. N. T. (2011). Readmissão em serviço de emergência: perfil de morbidade dos pacientes. Revista da Rede de Enfermagem do Nordeste, 12(3), 453-461. http://periodicos.ufc.br/rene/article/view/4258/3288

Brasil. (1988). Constituição da República Federativa do Brasil de 1988 Presidência da República. http://www.planalto.gov.br/ccivil_03/constituicao/constituicao.htm

Callegaro, G. D., Koerich, C., Lanzoni, G. M. de M., Baggio, M. A., \& Erdmann, A. L. (2012). Significando o processo de viver a cirurgia de revascularização miocárdica: mudanças no estilo de vida. Revista Gaúcha de Enfermagem, 33(4), 149-156. https://doi.org/10.1590/S1983-14472012000400019

Crossetti, M. da G. O. (2012). Revisão integrativa de pesquisa na enfermagem o rigor científico que lhe é exigido. Rev Gaúcha Enferm, 33(2), 8-9. https://www.scielo.br/pdf/rgenf/v33n2/01.pdf

Erdmann, A. L., Meirelles, B. H. S., Lanzoni, G. M. de M., Baggio, M. A., Higashi, G. D. C., Koerich, C., Cunha, K. S. da, \& Kahl, C. (2017). Paciente cardíaco revascularizado: processo de referência e contrarreferência dos serviços de saúde de Santa Catarina. Com. Ciências Saúde, 28(1), 91-95. http://bvsms.saude.gov.br/bvs/periodicos/ccs_artigos/paciente_\%20revasculaizado.pdf

Ferreira, S. R. S., Périco, L. A. D., \& Dias, V. R. F. G. (2018). A complexidade do trabalho do enfermeiro na Atenção Básica à Saúde. Revista Brasileira de Enfermagem, 71(1), 752-757. https://doi.org/10.1590/0034-7167-2017-0471

Galter, C., Rodrigues, G. da C., \& Galvão, E. C. F. (2010). A percepção do cardiopata para a vida ativa após recuperação de cirurgia cardíaca. J Health Sci Inst, 28(3), 255-258. http://repositorio.unip.br/journal-of-the-health-sciences-institute-revista-do-instituto-de-ciencias-da-saude/a-percepcao-do-pacientecardiopata-para-vida-ativa-apos-recuperacao-de-cirurgia-cardiaca/

Kahl, C., Cunha, K. S. da, Lanzoni, G. M. de M., Higashi, G. D. C., Erdmann, A. L., \& Baggio, M. A. (2018). Referência e contrarreferência: repercussões da revascularização miocárdica na perspectiva da Atenção Primária. Revista Brasileira de Enfermagem, 71(5), 2359-2366. https://doi.org/10.1590/0034-71672016-0598

Kaufman, R., Kuschnir, M. C. C., Xavier, R. M. A., Santos, M. A., Chaves, R. B. M., Müller, R. E., Pinheiro, M. C. C. M., Ribeiro, A. L. P., \& Azevedo, V. M. P. (2011). Perfil Epidemiológico na Cirurgia de Revascularização Miocárdica. Rev Bras Cardiol., $24(6), \quad 369-376$. http://www.onlineijcs.org/english/sumario/24/pdf/v24n6a05.pdf

Kirby, S. E., Dennis, S. M., Jayasinghe, U. W, \& Harri, M. F. (2010) Fatores relacionados ao paciente em readmissões frequentes: a influência da condição, acesso aos serviços e escolha do paciente. BMC Health Services Research, 10 (216), 1-8. https://doi.org/10.1186/1472-6963-10-216

Koerich, C., Lanzoni, G. M. de M., Meirelles, B. H. S., Baggio, M. A., Higashi, G. D. C., \& Erdmann, A. L. (2017). Perfil epidemiológico da população submetida à revascularização cardíaca e acesso ao sistema único de saúde. Cogitare Enfermagem, 22(3), 1-9. http://dx.doi.org/10.5380/ce.v22i3.50836

Kossovsky, M. P., Perneger, T. V., Sarasin, F. P., Bolla, F., Borst, F., Gaspoz, J. M. (1999). Comparação entre readmissões planejadas e não planejadas para um Departamento de Medicina Interna. Journal of Clinical Epidemiology, 52(2), 151- 156. https://doi.org/10.1016/S0895-4356(98)00142-5

Lanzoni, G. M. de M., Koerich, C., Meirelles, B. H. S., Erdmann, A. L., Baggio, M. A., \& Higashi, G. D. C. (2018). Revascularização miocárdica: referência e contrarreferência do paciente em uma instituição hospitalar. Texto \& Contexto - Enfermagem, 27(4), 1-10. https://doi.org/10.1590/0104-07072018004730016

Lima, D. W. da C., Vieira, A. N., \& Silveira, L. C. (2015). A escuta terapêutica na clínica de enfermagem em saúde mental. Texto \& Contexto Enfermagem, 24 (1), 154-160. https://doi.org/10.1590/0104-07072015002450013

Ministério da Saúde. (2012). Política Nacional de Atenção Básica. Ministério da Saúde, 1(1), 9-26. http://189.28.128.100/dab/docs/publicacoes/geral/pnab.pdf Ministério da Saúde. (2017). Principais causas de morte. Departamento de análise de saúde e vigilância de doenças não transmissíveis. Secretaria de vigilância em saúde. http://svs.aids.gov.br/dantps/centrais-de-conteudos/paineis-de-monitoramento/mortalidade/gbd-brasil/principais-causas/

Ministério da Saúde. (2020). Sistema Único de Saúde (SUS): estrutura, princípios e como funciona. Governo Federal. https://www.gov.br/saude/ptbr/assuntos/saude-de-a-a-z-1/s/sistema-unico-de-saude-sus-estrutura-principios-e-como-funciona

Miotello, M., Koerich, C., Lanzoni, G. M. de M., Erdmann, A. L., \& Higashi, G. D. C. (2020) Atuação do enfermeiro na consolidação do cuidado longitudinal à pessoa com doença arterial coronariana. Revista de Enfermagem da UFSM, 10(49), 1-20. https://doi.org/10.5902/2179769234628

Nery, R. M., Barbisan, J. N., \& Mahmud, M. I. (2007). Influência da prática da atividade física no resultado da cirurgia de revascularização miocárdica. Rev Bras Cir Cardiovasc, 22(3), 297-302. https://doi.org/10.1590/S0102-76382007000300005

Oliveira, R. M. de, Sena, Z. G. F. de, Frota, L. M. da C. P., \& Oliveira, J. B. B. de. (2010). Qualidade de vida de mulheres submetidas à cirurgia de revascularização do miocárdio em um hospital público. Rev Bras Promoç Saúde (RBPS), 23(3), 237-242. https://periodicos.unifor.br/RBPS/article/view/2022/2317\#

Oliveira, E. L. de, Westphal, G. A., \& Mastroeni, M. F. (2012). Características clínico-demográficas de pacientes submetidos a cirurgia de revascularização do miocárdio e sua relação com a mortalidade. Rev Bras Cir Cardiovasc, 27(1), 52-60. https://doi.org/10.5935/1678-9741.20120009

Oliveira, A. P. D. de, Cavalcante, A. M. R. Z., Carneiro, C. de S., Santos, V. B., Moorhead, S., Lopes, J. de L., \& Barros, A. L. B. L. de. (2020). Educação em saúde: a eficácia das intervenções em pacientes com insuficiência cardíaca. Revista Brasileira de Enfermagem, 73(2), 1-8. https://doi.org/10.1590/0034-71672018-0782

Organização Pan-Americana da Saúde. (2017). Doenças cardiovasculares. https://www.paho.org/bra/index.php?option=com_content\&vie $\mathrm{w}=$ article \&id $=5253$ :doencas-cardiovasculares $\&$ Itemid $=1096$

Organização Pan-Americana da Saúde. (2018). Folha informativa - Transtornos mentais. https://www.paho.org/bra/index.php?option=com_content\&vi ew $=$ article \&id=5652:folha-informativa-transtornos-mentais \&Itemid=839 
Research, Society and Development, v. 10, n. 4, e38910414542, 2021

(CC BY 4.0) | ISSN 2525-3409 | DOI: htttp://dx.doi.org/10.33448/rsd-v10i4.14542

Organização Pan-Americana da Saúde. (2019). Folha informativa-Tabaco. www.paho.org/bra/index.php?option=com_content\&view=article\&id=5641:folhainformativatabaco\&Itemid $=0$

Organização Pan-Americana da Saúde. (2020). Doenças cardiovasculares. https://www.paho.org/pt/topicos/doencas-cardiovasculares

Pietrobon, R. C., \& Barbisan, J. N. (2010). Impacto da cirurgia de revascularização do miocárdio na cessação do tabagismo. Rev Bras Cir Cardiovasc, 25(1), 79-84. https://doi.org/10.1590/S0102-76382010000100017

Resolução $\mathrm{n}^{\circ}$ 510, de 07 de abril de 2016. (2016). Dispõe sobre as normas aplicáveis a pesquisas em Ciências Humanas e Sociais. https://bvsms.saude.gov.br/bvs/saudelegis/cns/2016/res0510_07_04_2016.html\#: :text=1\%20o\%20Esta\%20Resolu\%C3\%A7\%C3\%A3o\%20disp\%C3\%B5e,e xistentes $\% 20$ na $\% 20$ vida\%20cotidiana $\% 2 \mathrm{C} \% 20$ na

Ribas, E. do N., Bernardino, E., Larocca, L. M., Neto, P. P., Aued, G. K., \& Silva, C. P. C. da. (2018). Enfermeira de ligação: uma estratégia para a contrarreferência. Revista Brasileira de Enfermagem, 71 (Supl. 1), 546-553. https://dx.doi.org/10.1590/0034-7167-2017-0490

Soares, G. M. T., Ferreira, D. C. de S., Gonçalves, M. P. C., Alves, T. G. de S., David, F. L., Henriques, K. M. de C., \& Riani, L. R.. (2011). Prevalência das Principais Complicações Pós-Operatórias em Cirurgias Cardíacas. Rev Bras Cardiol., 24(3), 139-146. http://sociedades.cardiol.br/socerj/revista/2011_03/a_2011_v24_n03_01prevalencia.pdf

Souza, M. T. de, Silva, M. D. da, \& Carvalho, R. de. (2010). Revisão integrativa: o que é e como fazer. Einstein, 8 (1), 102-106. https://doi.org/10.1590/s167945082010rw1134

Stevens, B., Pezzullo, L., Verdian, L., Tomlinson, J., George, A. \& Bacal, F. (2018). A carga econômica das doenças cardíacas no Brasil. Arquivos Brasileiros de Cardiologia, 111 (1), 29-36. https://doi.org/10.5935/abc.20180104

Whittemore, R, \& Knafl, K. (2005). The integrative review: updated methodology. Journal of Advanced Nursing, 52(5), 546-553. http://dx.doi.org/10.1111 / j.1365-2648.2005.03621.x

World Health Organization. (2018). The top 10 causes of death. https://www.who.int/news-room/fact-sheets/detail/the-top-10-causes-of-death

World Health Organization. (2019). The Impact Of Chronic Disease In Brazil: Chronic diseases are the major. https://www.who.int/chp/chronic_disease_report/media/brazil.pdf?ua=1 